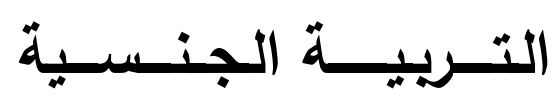

د/هشام عبد الحميد تهامى

قسم علم النفس - جامعة بنى سويف عبد تهامى
د/ نرمين عبد الوهاب أحمد صالح

قسم علم النفس - جامعة بنى سويف عبد التماب

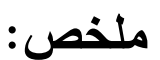

هاف البحث الراهن إلى تناول موضوع التريبة الجنسية؛ حيث تم عرض أسباب الاهتمام بالتربية الجنسية، وتعريف التربية

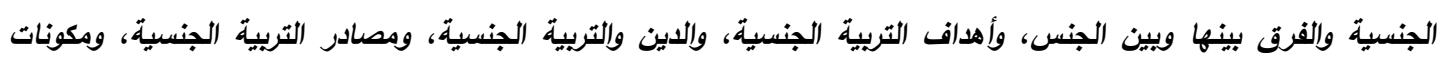

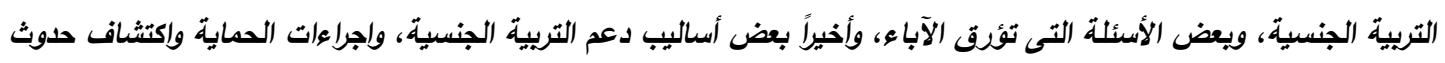

إساءة جنسية.

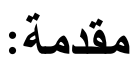

إن حياة الإنسان سلسلة انتقالات من مرحلة ارتقائية إلى أخرى، ولا شكك أن توافق المريء مع كل مرحلة

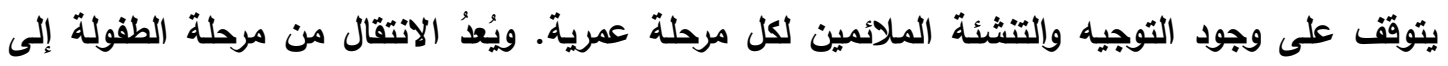

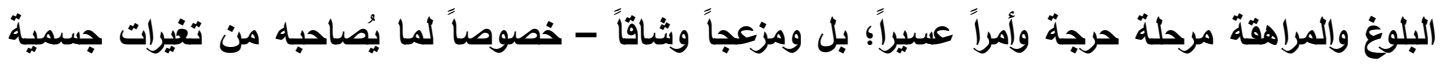

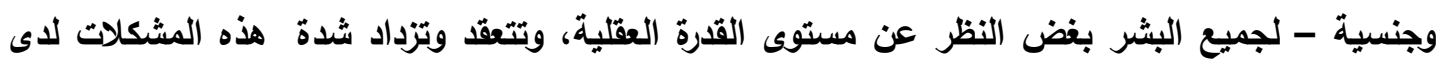

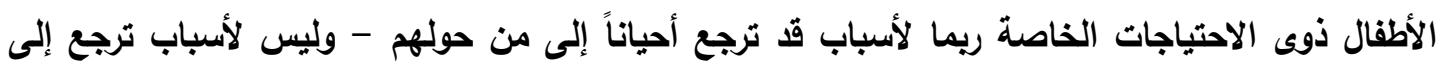

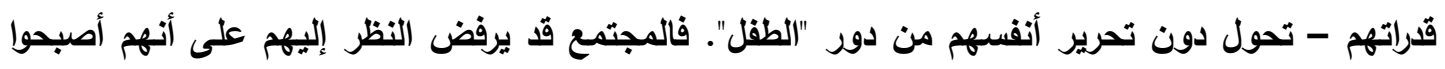

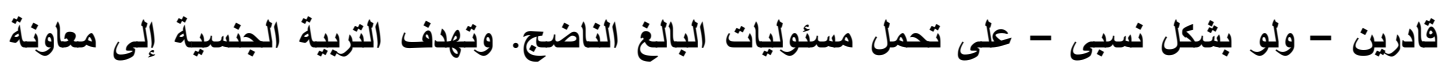

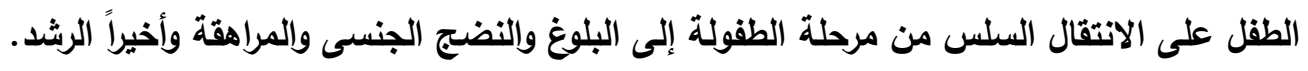

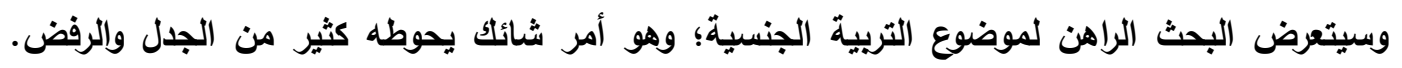
وهناك أسباب عديدة دفعت الباحثين للاهتمام بموضوع التربية الجنسية خاصة فى سنوات العمر المبكرة، ومن الجنات

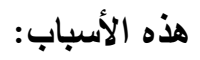
1. عملهما منذ سنوات بعيدة في مجال رعاية الأيتام والأطفال ذوى الاحتياجات الخاصة.

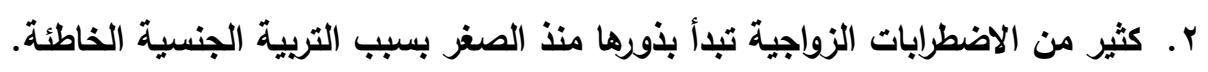

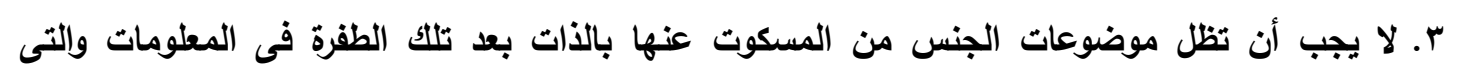
يجانب كثير منها الصواب.

؛ ـ ـ نشر الوعى السليم بالتربية الجنسية وكيف نقوم بها كمربين أو رعاة.

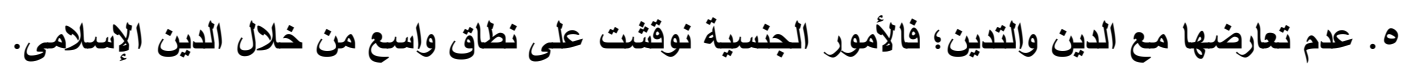

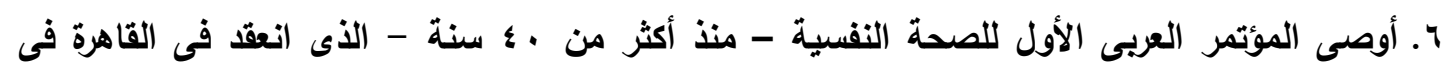

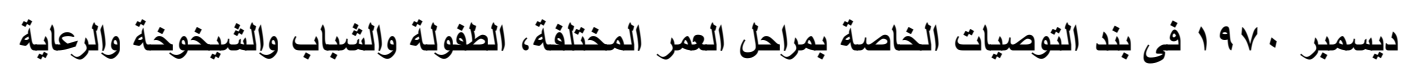
الأسرية، بخصوص التربية الجنسية ما يلى: 
"ضرورة العمل على نشر الثقافة الأسرية بما فى ذلك الثقافة الجنسية منذ سن مبكرة فى إطار التقاليا والعادات الخاصة بمجتمعنا لما لهذه الثقافة من آثار بناءة فى تكوين الفرد والأسرة والمجتمع." (حامد

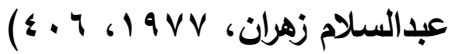
ويمكن تعريف التربية الجنسية بأنها "كل الجهود المنظمة التى تقوم بها المؤسسات والهيئات التريوية والأسرة لتعليم الأطفال كافة الجواتب الحيوية العضوية والنفسية والاجتماعية الثقافية المرتبطة بالوظيفة الجنسية لاى البشر، بهاف إحداث تغييرات إيجابية واضحة فى مكونات الثخصية ذات العلاقة بالوظيفة

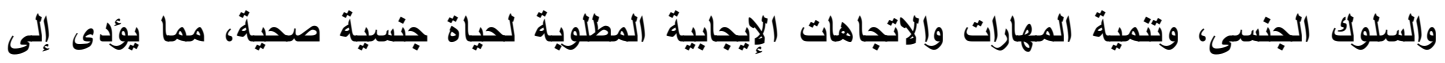
السعادة والرضا الناتج عن الوظيفة والسلوك الجنسى. كما تتصدى التربية الجنسية كذلك إلى صور الخلل أو الو التهايه الثذوذ فى هذه الوظيفة مثل العنف الجنسى والأمراض الجنسية" (Ozalap, Bombas, Trindade \&

.Branco, 2001)

ويعبارة أخرى يمكن القول أن التربية الجنسية تهدف إلى إمداد الفرد بالمعلومات العلمية والاتجاهات الصحيحة نحو الأمور الجنسية، بقر ما يسمح به نموه الجسمى والفسيولوجى والعقلى والانفعالى

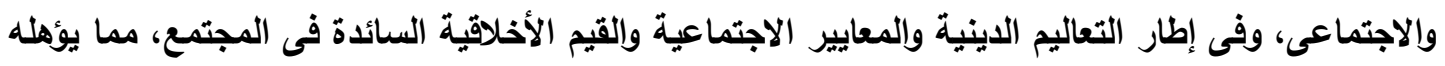
للتوافق النفسى وحُسن التصرف فى المواقف الجنسية ومواجهة مشكلاته الجنسية فى الحاضر والمستقبل بطريقة واقعية تؤدى إلى الصحة النفسية. ويجب أن نفرق هنا بين الجنس' والجنسيةٌ فالجنس يُقصد به فعل أى شئ له طبيعة جنسية (عادة تتضمن الأعضاء التناسلية). أما كلمه الجنسية أو التربية الجنسية فهى أوسع كثيراً وأعقد؛ حيث أن أنهية الجنسية تثمل ملامح أساسية لنا نحن كبشر، وكجزع نشط وغير منفصل عنا. ويعبارة أخرى يمكن التفرقة

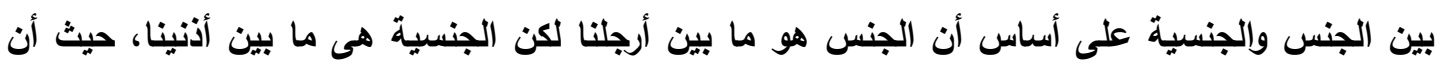

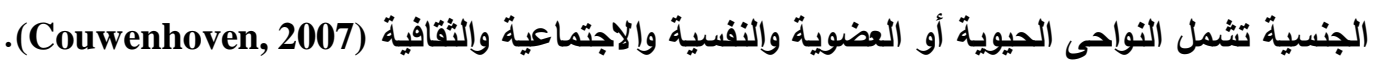
ويجب أن نشير إلى أن موضوع التربية الجنسية يلقى معارضة لدى الآباء والأمهات، بل والمجتمع بأسره.

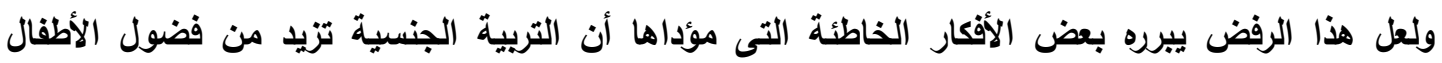
والمراهقين وتزيد من اهتمامهم بالأمور الجنسية ويالتالى محاولة التجريب. ورغم الوجاهة الظاهرية لهذه لهاه الفكرة إلا أنتا نغفل بذلك المصادر الأخرى - كوسائل الإعلام المنتشرة بكثرة الآن وكذلك جماعات الألكور الأقران -

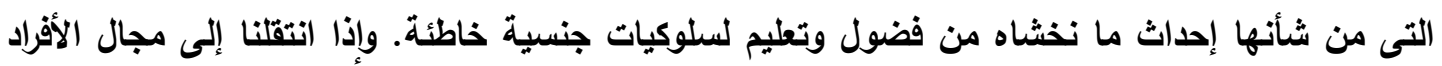

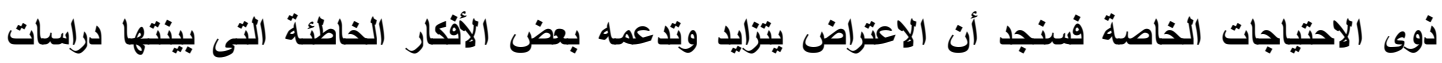

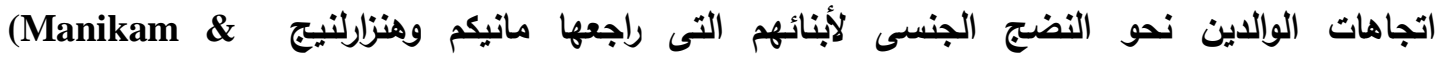
Hensarling, 1990)

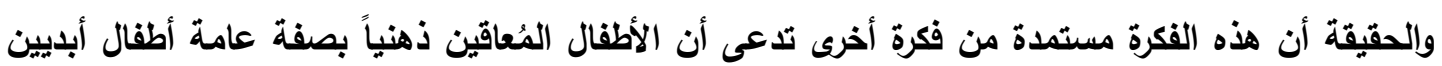

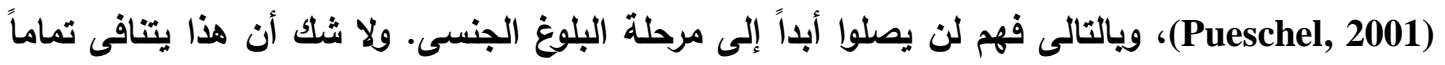
مع ما أثار إليه عديد من الاراسات عن النضج الجنسى لاى الأفراد ذوى الإعاقات الذهنية (هثام

1. Sex.

2. Sexuality 


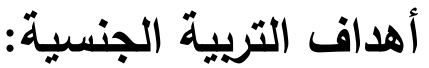

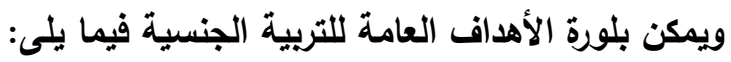

1- تزويد الأطفال والمراهقين بالمطلومات الدقيقة عن النضج والتكوين التشريحى للجسم، وفسيولوجيا ئهيه السلوك الجنسى وولادة الأطفال والحياة الأسرية، و الإساءة الجنسية.

$$
\text { r - تنمية القيم ذات الصلة بالسلوك الجنسى. }
$$

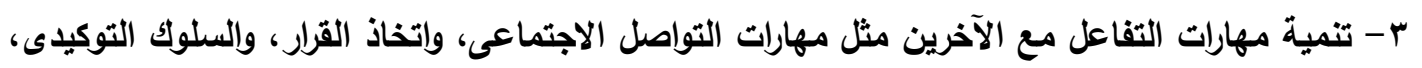

ومقاومة الضغوط.

\section{ع - تنمية المسئولية الشخصية عن الممارسة الجنسية.}

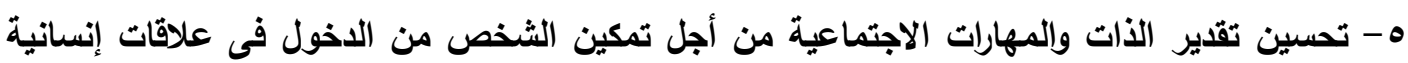

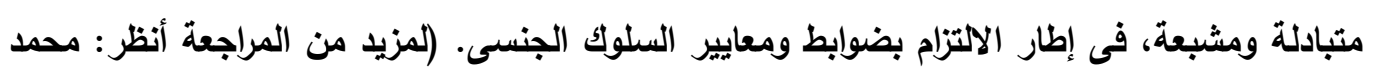

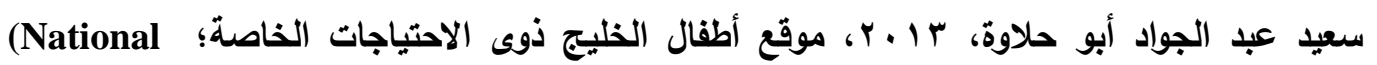

.Information Center for Children and Youth with Disabilities,1992)

$$
\text { التربية الجنسية والدين: }
$$

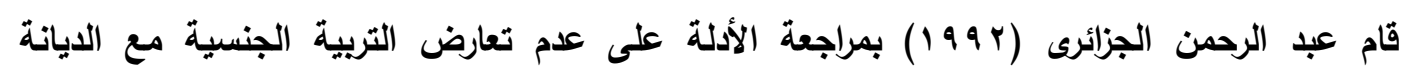

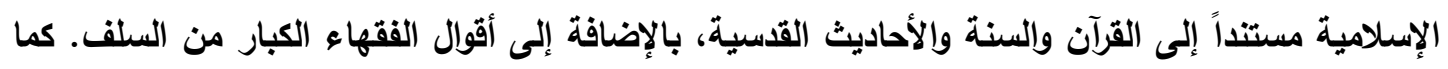

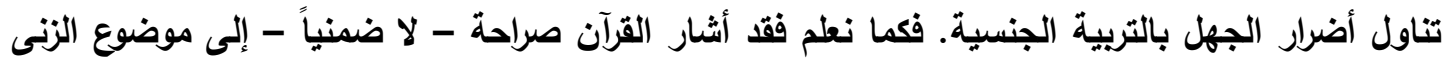

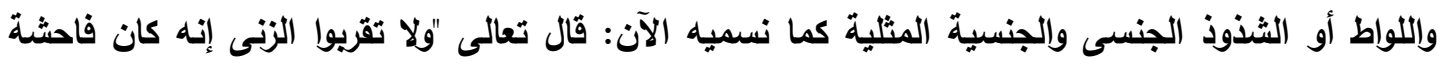

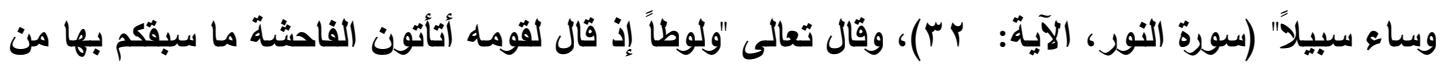
أحد من العالمين، إنكم لتأتون الرجال شهوة من دون النساء، بل أنتم قوم مسرفون" (سورة الأعراف، الآيتين

$$
\cdot(\Lambda) ، \Lambda \text {. }
$$

هذا عن بعض الإشارات عن موضوعات جنسية كما وردت فى القرآن فماذا عن الحديث القدسى؟ نشير هنا قبل أن نتعرض لذلك إلى أن علماء النفس الحديث تحدثا عن العملية الجنسية مفرقين بين ما أسموه أرجاع ممهة وأرجاع مكملة. ويدخل فى إطار الأرجاع الممهدة الإقتراب من المرأة والنظر إليها وتقبيلها....

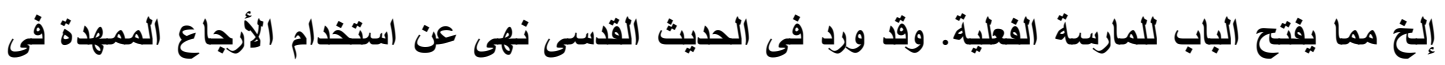

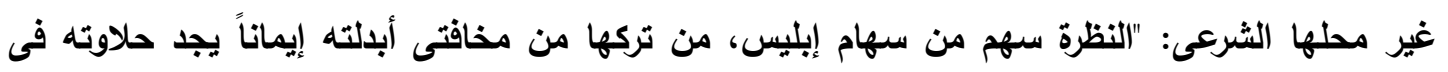

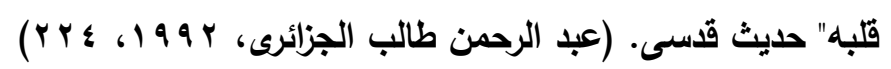
واستفاضت الأحاديث النبوية فى أسس وقواعد التربية الجنسية، فكم من أحاديث تناولت الحيض والغنل

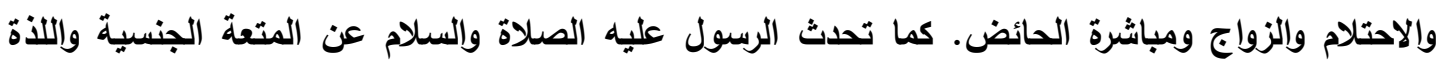

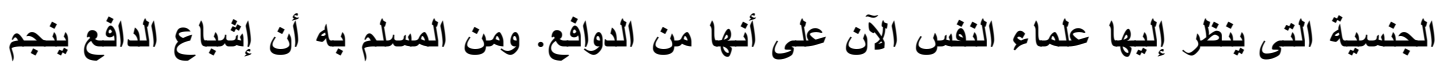

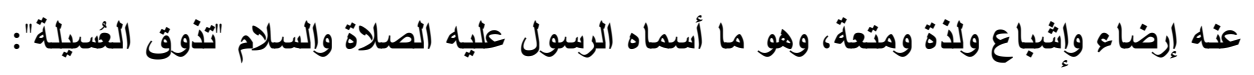
"قال الثافعى أخبرنا سفيان بن عيينة عن إبن شهاب عن عروة عن عائشة زوج التبى صلى الثى الله عليه

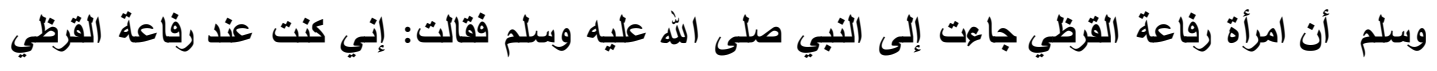
فطلقى، فتزوجت عبد الرحمن بن الزبير وإنما معه مثل هلبة الثوب، فتبسم رسول الله صلى الله عليه وسلم وقال: تريدين أن ترجعي إلى رفاعة؟ لا حتى تذوقي عسيلته ويذوق عسيلتك" (المكتبة الإسلامية على شبكة 
وحتى النوم وما يرتبط من غرائز جنسية اهتم به الحديث الثريف فتحدث عن سن التفرقة فى المضاجع

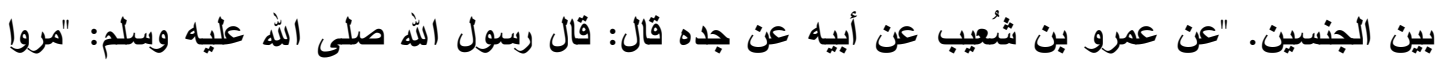

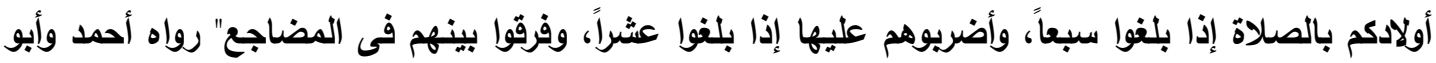

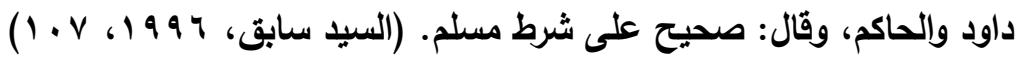
وانطلاقاً مما سبق أسهب الفقهاء فى الحديث عن أمور جنسية تشمل الحديث عن البكارة والطهارة والخطبة والزواج والمعاشرة الجنسية... إلخ. نخلص مما سبق إلى أن الاهتمام بالتربية الجنسية أمر هام وله سند دينى.

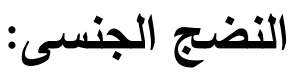

بالرغم من أن التربية الجنسية يجب أن تبدأ مبكراً منذ استكشاف الطقل الأولى لأعضاء جسمه - ويصفة خاصة الجنسية منها - إلا أن ثمارها تتجلى بشدة مع حدوث النضج الجنسى الذى يبزغ بثدة في مراحل ما قبل البلوغ والبلوغ والمراهقة وما قبلها وما بعدها. ومن هذا المنطلق أفرد الباحثان فى الفقرات التالية عرضاً لمظاهر البلوغ والنضج الجنسى وأسسهما الفسيولوجية.

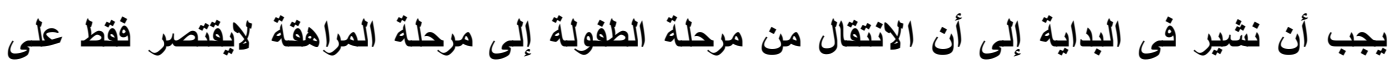
التغيرات الجنسية، ولكنه يشمل تحديات اجتماعية أخرى تثمل التوافق الدراسى والمهنى (لمزيد من المراجعة الإنه

فى ذلك أنظر: Pueschel, 2001 ). وعندما تبأ الأعضاء التناسلية فى أداء وظائفها تنتهى مرحلة الطفولة وتبدأ مرحلة المراهقة المبكرة،

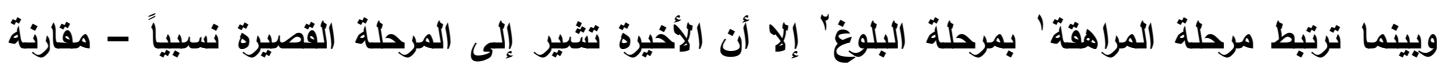

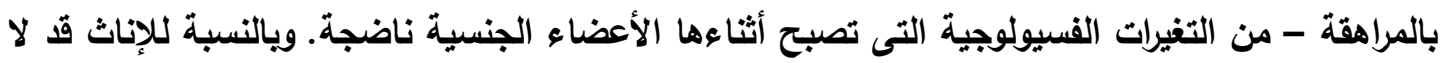

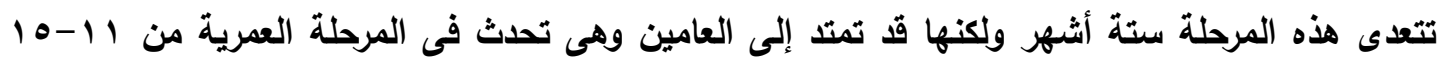

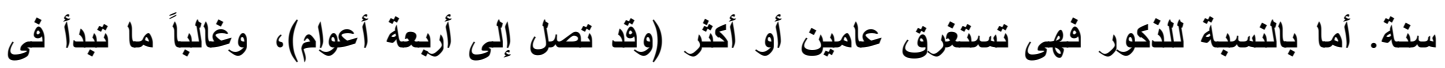

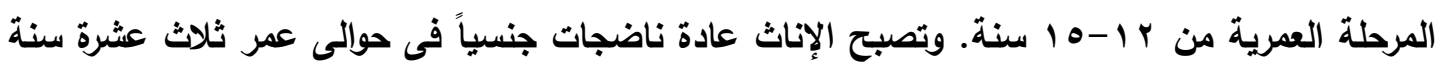

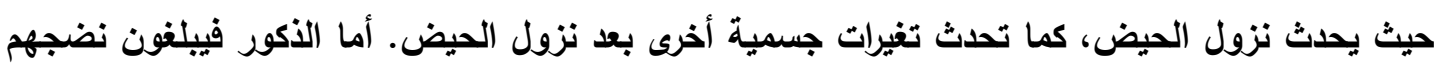

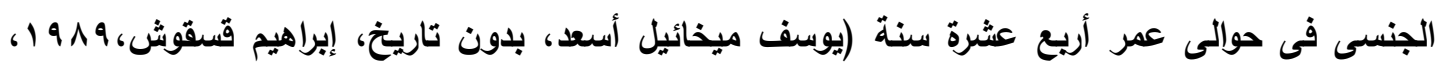

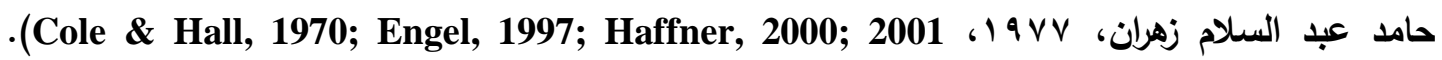
ويالقطع هناك فروق فردية فى هذا العمر عند البلوغ لاى الجنسين. وقد بيَّت المراجعة القديمة التى قام بها

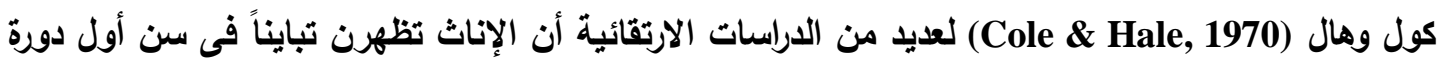

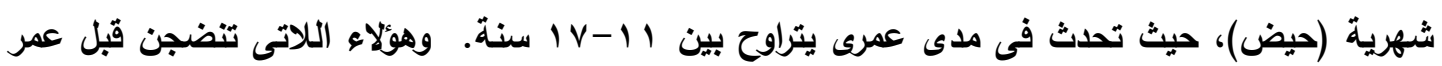
الثانية عشرة من العمر تعتبرن ذوات نضج مبكر"، أما اللاتى تتضجن في عمر خمس عشى عشرة سنة أو أو بعدها

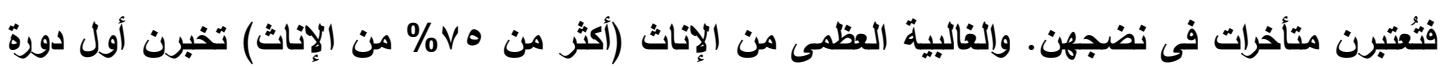

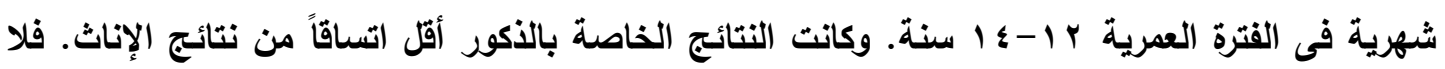
توجد سن محددة عندها يصبحون ناضجين جنسياً. فالطقل العادى يحتاج عامين تقريباً كى ينتقل من مرحلة قبل البلوغ" إلى مرحلة ما بعد البلوغ'. وقث أوضحت نتائج الدراسات التى راجعها كول وهال (1970) أن

\footnotetext{
1 - adolescence.

2 - puberty.

3 - precocious

4 - prepubescent
} 
الأكور يصلون إلى مرحلة النضج متأخرين حوالى سنتين عن الإناث. ولذلك فحصر الإناث الناضجات فى فترة عمرية ما قد يتجاوز بكثير الذكور الناضجين. وقد تجد أنثى عمرها ثلاث عشرة سنة قد أصبحت إمرأة ألثات

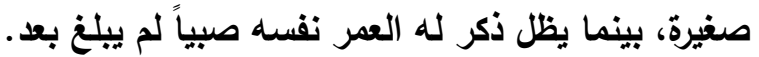

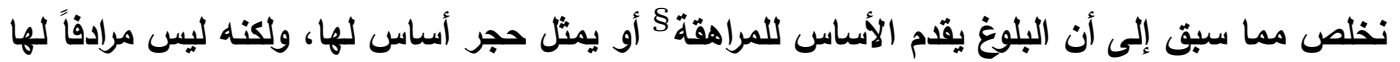

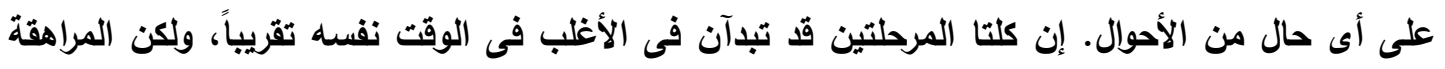
تستمر لحوالى ثمانية أعوام، وهى لا تتضمن فقط تغيرات البلوغ فى الجسم والأعضاء التخاسلية، ولكنها

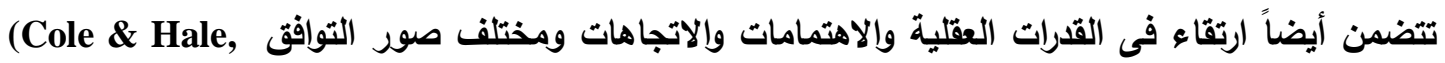
.1970; Engel,1997; Haffner, 2000;2001) وترجع أسباب التغيرات فى مرحلة البلوغ إلى زيادة نشاط بعض الغدد الصماء؛ وتحديداً الغدة النخاميةّ

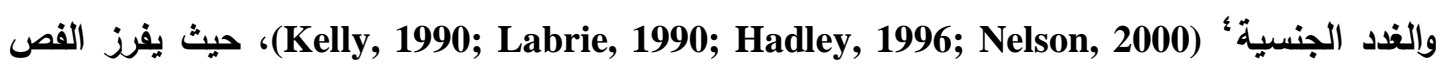
الأمامى من الغدة النخامية التى توجد فى قاع الجمجمة نوعين من الهرمونات يرتبطان بتغيرات البلوغ؛ وهما هرمون النمو الذى يساعد على نمو حجم الجسم، والثانى هرمون منبه وحافز للغدد الجنسية يؤدى إلى نونى

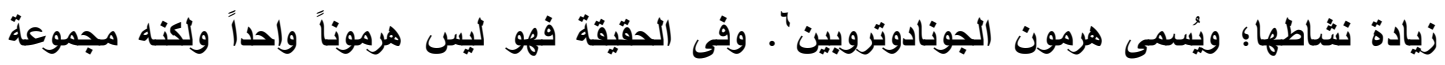

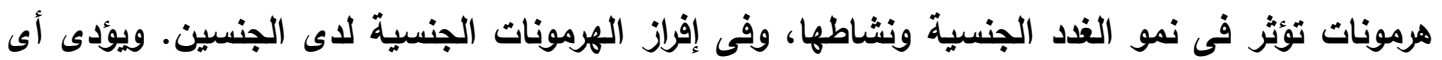
نقص فى إفراز هرمون الجونادوتروبين إلى توقف نمو الجهاز التناسلى". وتثمل مجموعة الجونادوتروبين

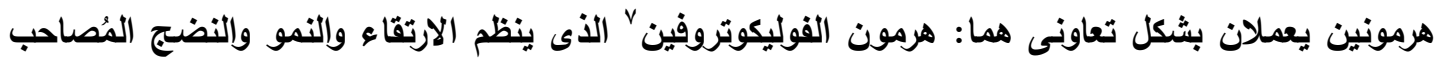

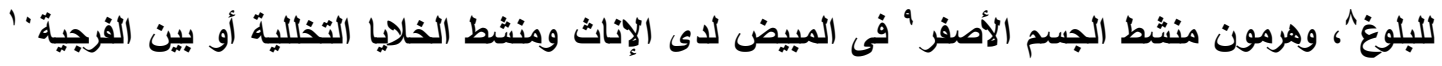

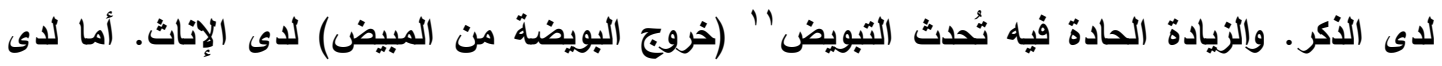

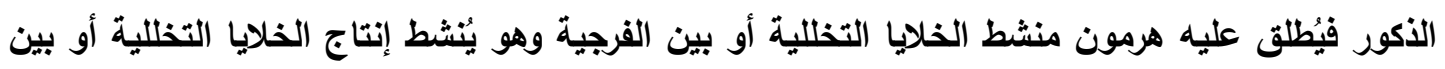

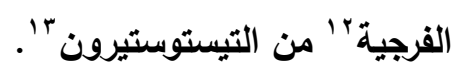

وتزداد إفرازات الغدة النخامية من هرمونى النمو والثهرون المحفز للغدد الجنسية (الجونادوتروبين) قبل مرحلة البلوغ مباشرة. ويتزايد إفرازها أكثر فأكثر خلال مرحلة البلوغ، ويتحكم في العملية بكاملها التغيرات

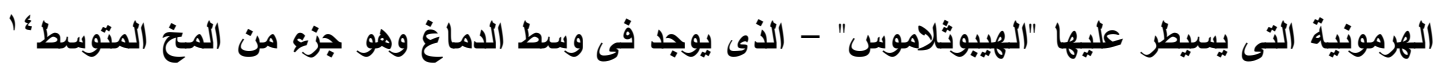

\footnotetext{
1 - postpubescent

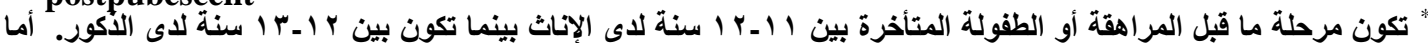

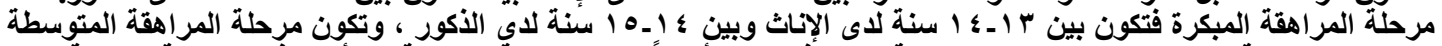

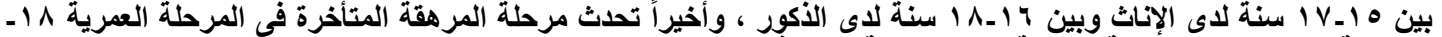

2 - Endocrine glands .

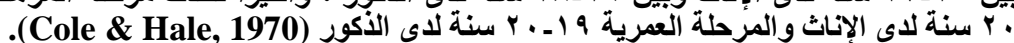

3 - Pituitary gland.

4 - Gonads.

5 - Growth hormone.

6 - Gonadotropin hormone.

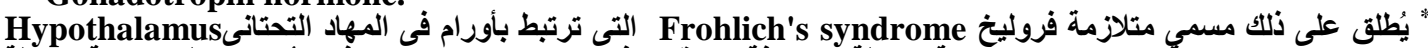

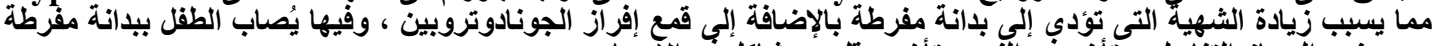
${ }_{8}^{7}$ - Follicle-stimulating hormone (FSH).

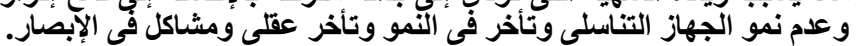

8 - Pubertal maturation.

9 - Luteinizing hormone.

10 - Interstitial cell stimulating hormone (ICSH).

11 - Ovulation.

12 - Leydig cell or interstitial cells of leydig.

13 - Testosterone.

14 - Diencephalon.
} 
- والمعروف بأنه المسئول عن استثارة آلية البلوغ" (Racadot,1990). ويالرغم من أن الغددالجنسية تكون موجودة ونثطة أثناء الولادة، إلا أن نشاطها يزداد أثناء مرحلة البلوغ نتيجة الهرمون الجنسى الذئى تفرزه

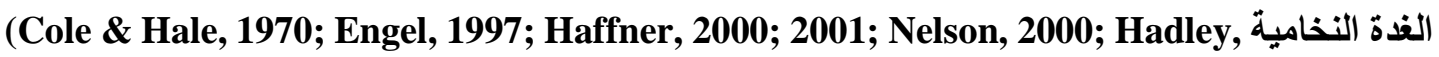

وتُعدُ الخصيتان' هما الغدد الجنسية لدى الأكر، وهما يُقرزان نوعين من الإفرازات أحدهما خارجى ويتمثل

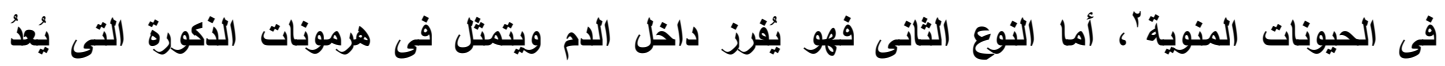
التيستوستيرون أهمها وأثهرها. ويخضع عمل الخصيتين - سواء إفراز الحيوانات المنوية أو الهرمونات الجنسية - لتحكم هرمونات الجونادوتروبين (هرمون الفوليكوتروفين وهزمون منشط الجسم الأصفر فى الفين

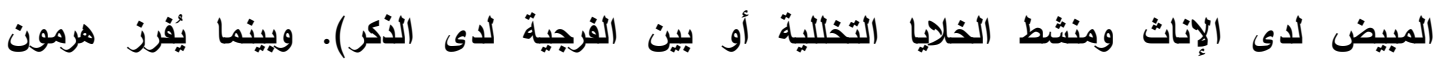

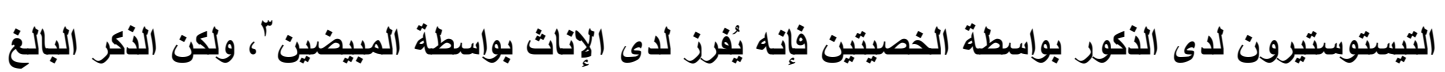

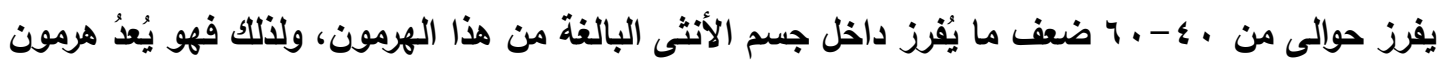

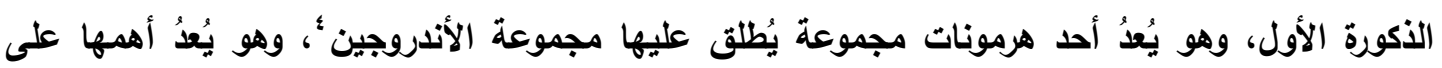

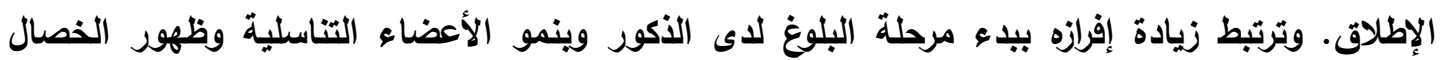

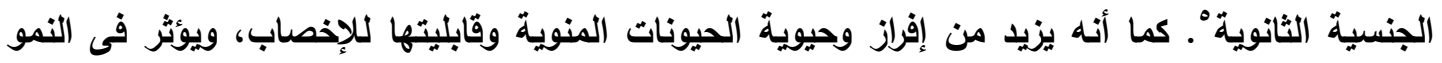
الانفعالى للمراهق ويقوى لايه الدافع الجنسى. أما الغدد الجنسية لاى الإناث فهى المبيضان ويفرزان أيضاً نوعين من الإفراز أولهما خارج الام وهو

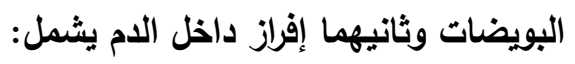

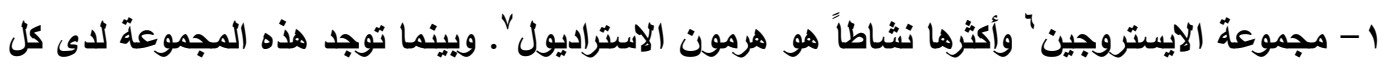

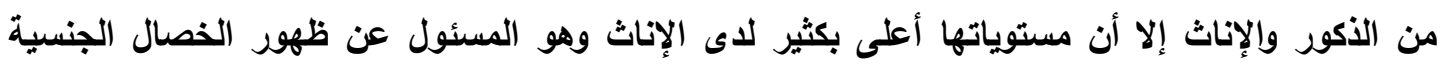

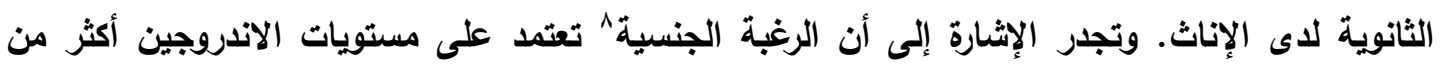
إعتمادها على مستويات الايستروجين.

ب - هرمون البروجستيرون": يُطلق عليه هرمون الحمل ' فهو يهئ الرحم لقبول البويضة المئلقحة

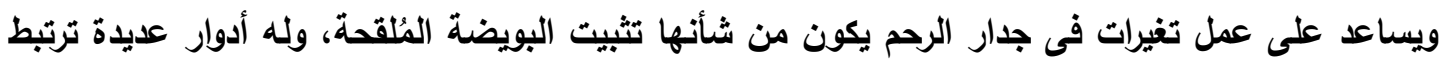
بنمو وارتقاء الجنين فى الرحم.

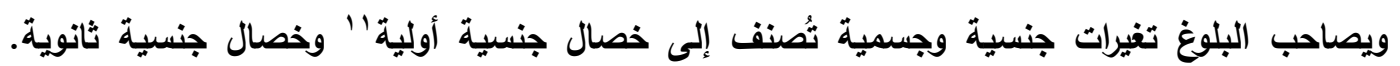

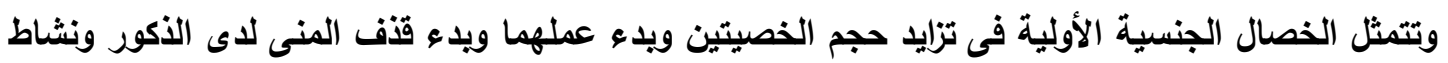

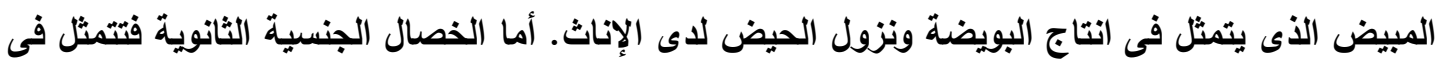

* لا يُعتبر المهاد التحتنانى هو الجزء المخي الوحيد الذى يؤدى دوراً فى البلوك الجنسى ، وإنما هناك أجزاء أخرى كالنواة اللوزية Amygdala

1 - Testicles.

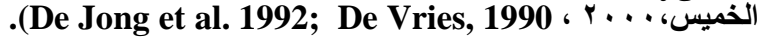

- Sperms.

3 - Ovaries.

4 - Androgens

5 - Secondary sexual characteristics.

6 - Oestrogens.

7 - Oestradiol.

8 - Sexual desire.

9 - Progesterone.

10 - Hormone of pregnancy.

11 - Primary sexual characteristics . 
ملامسح الجسم التى تميز الذكور عن الإناث، ومن أهم معالمها حدوث طقرة فى النمو الجسمى ونمو

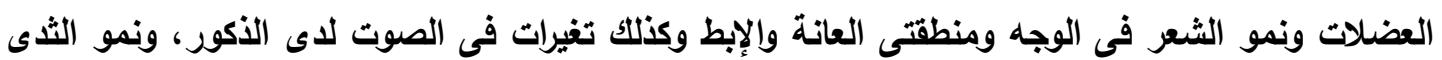
والمقعدة وطفرة جسمية وظهور شعر كثيف فى الإبط والعانة لاى الإناث، وترسيب وتوزيع الدهون فى جسم

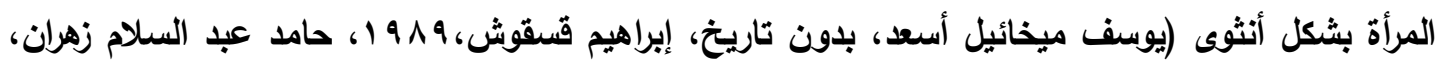
19v V يظهان تبايناً فى اتجاهاتهما نحو هذه التغيرات التى تحدث فى أجسامهم، وقد تؤثر هذه الاتجاهات فى

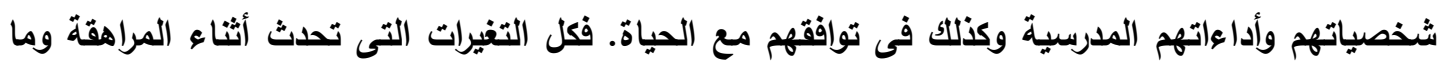
يصاحبها من نضج جنسى يكون له تأثير دال وعميق على سلوك واهتمامات كل من الذكور والإناث. وما من

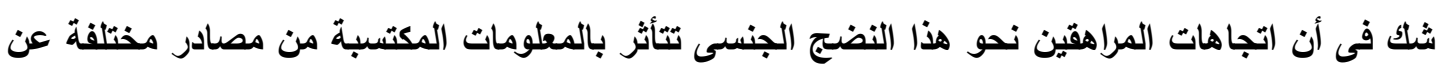
الجنس مثل الأباء والمناظرين لهم فى المرحلة العمرية نفسها والأخوة والأصدقاء والمدرسين والإعلام وإلكتب

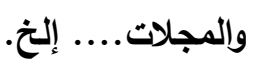

ومن المألوف أن يحاول المراهق بدعاً من المراهقة المبكرة أن يهائ من توتره الجنسى من خلال ما

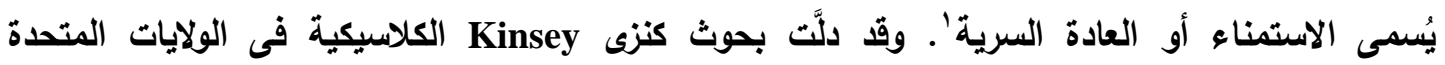

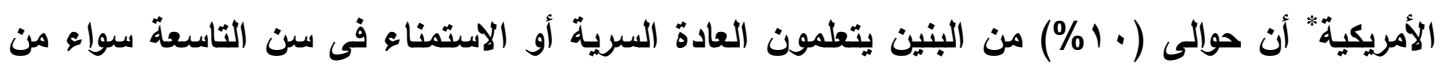
أقرانهم أو من تلقاء أنفسهم. وتزداد النسبة لتصل ذروتها أنها في سن الخامسة عشر حيث تبلغ نسبة البنين

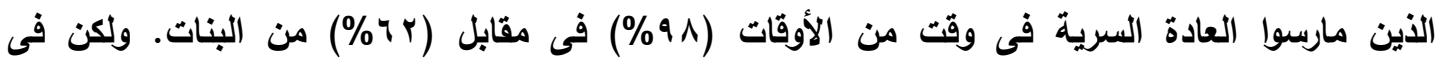

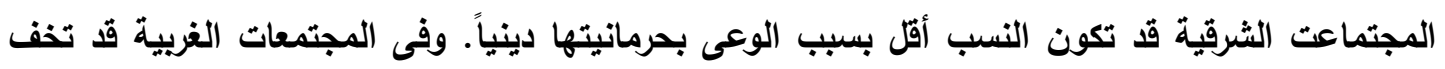

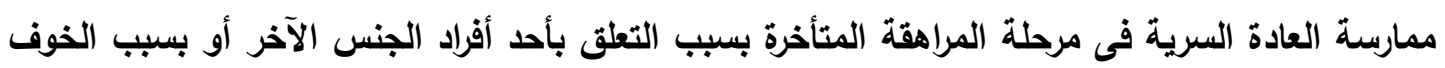

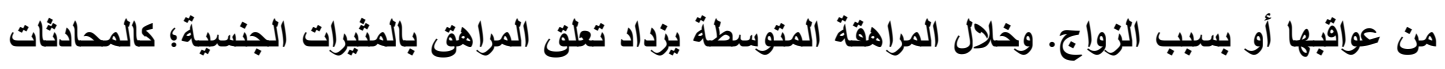

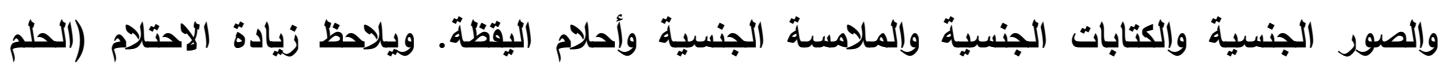
الجنسى) عند من يتجنبون العادة السرية (حامد عبد السلام زهران،

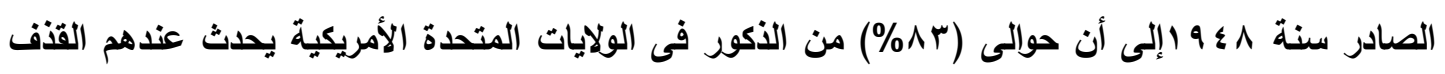

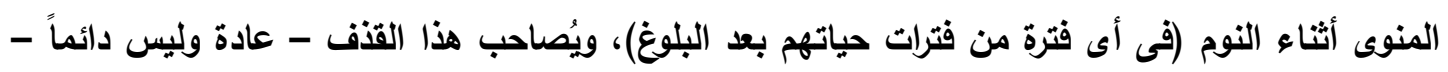
أحلاماً جنسية.

وهناك أدلة على أن ارتقاء الأفراد المُعاقين عقلياً يتبع المسار الارتقائى نفسه والقوائم الارتقائية للأفراد

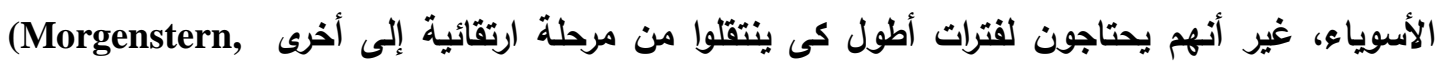
1973; Maksym, 1990)

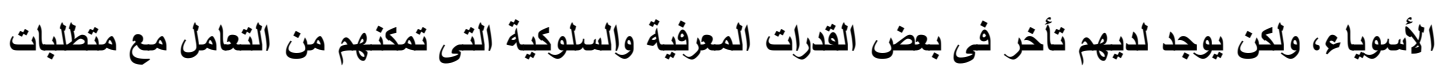

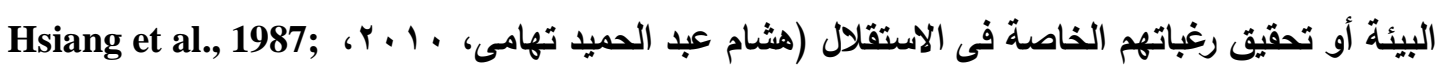
McCoy, 1991; Pueschel, 2001; Pueschel \& Bier, 1992; Schupf et al., 2003; Scola \& Pueschel, 1992; Van Dyke et al., 1996 ). والحقيقة أنه منذ عقود قليلة مضت كان يُنظر إليهم على

\footnotetext{
1 - Masturbation .

" راجع في ذلك كتابه الصادر سنة وئ 19 تحت عنوان "Sexual behavior in the human male" والذى غرفت بإسم

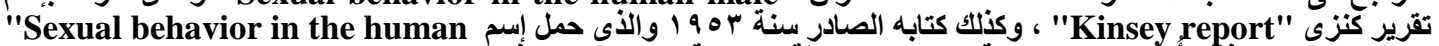

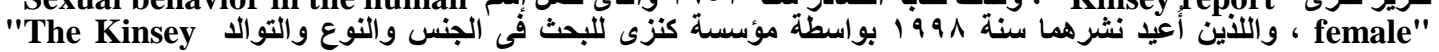
Institute for Research in Sex, Gender and Reproduction"

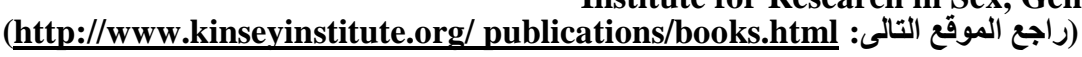


أنهم " أطفال أبديين ا"*، ولذا كانوا يتعرضون لكافة سبل الحماية والعزل، ولم يكن يُسمح لهم بالتعبير عن

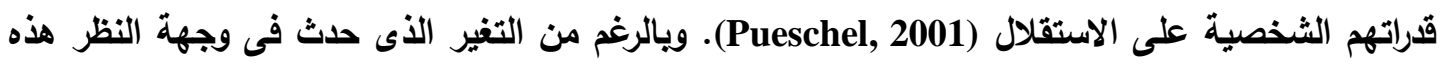

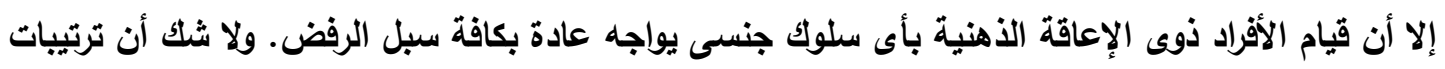

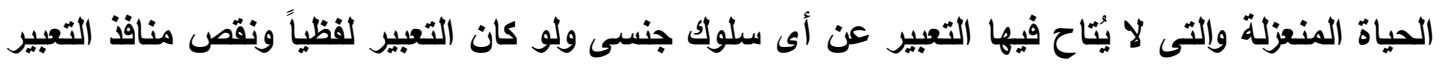
الاجتماعى المتاحة للأفراد ذوى الإعاقات العقلية يدلان على رفض الماح المجتمع للاوافع الجنسية لدى هولاء

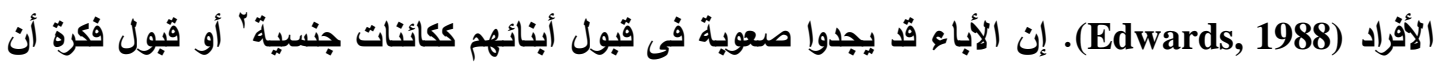
لايهم حاجات جنسية. وفى هذا الصدد يشير نجرو (Nigro, 1975) بعد عدة ملاحظات قام بها إلى أن أبوى فئو الطقل المُعاق قد يتعاملون معه على أنه سيظل طفلاً طيلة عمره أو ستظل علاقتهه به عله علاقة الطفل بأبويه، وهذا التصور قد يظهر فى عدة أوجه؛ منها مثلاً أن أوقاته وأنشطته متمركزة حول العائلة، كما أن علاقاته

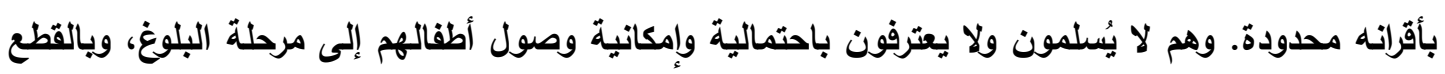

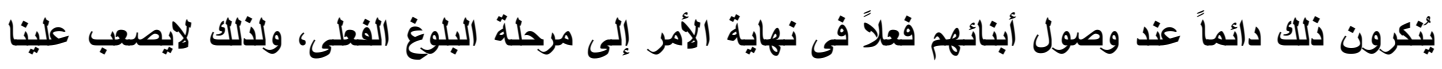

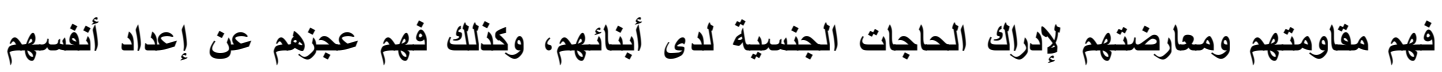

$$
\text { وطقلهم لمستقبل جنسى صحى. مصادر التربية الجنسية: }
$$

هناك مصدران أساسيان للتربية الجنسية يقدمان صوراً من التربية الجنسية المباشرة وغير المباشرة:

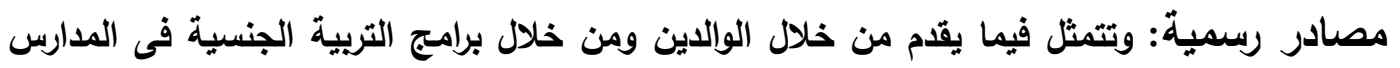

والمؤسسات التعليمية المختلفة.

مصادر غير رسمية: وتتمثل فى دور العبادة، ووسائل الإعلام، وجماعات الأقران والأصدقاء، والأفلام

والمجلات الإباحية....إلخ.

مكونات التربية الجنسية وسلوكيات الحماية:

تُعدُ المشاعر وتقدير الذات والصداقات ولغة التواصل مفاهيماً هامة فى الارتقاء الانفعالى للأطفال وبصفة الجاته

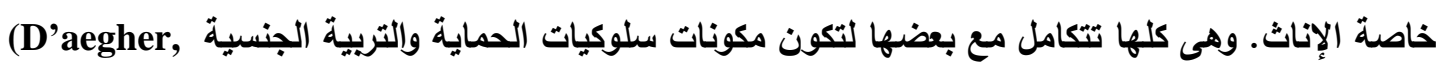
Robinson, Jones \& Collier, 1999)

$$
\text { وزملاؤه (1999): }
$$

إن جزعاً من الحياة اليومية للبشر وتفاعلاتهم الناجحة مع الآخرين تتطلب أن نكون قادرين على تحديد

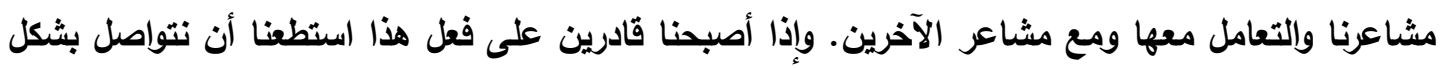

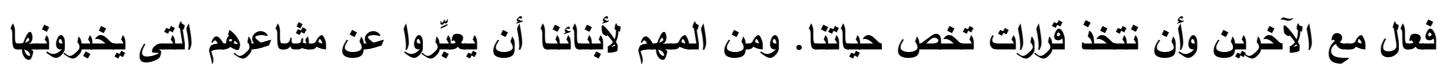

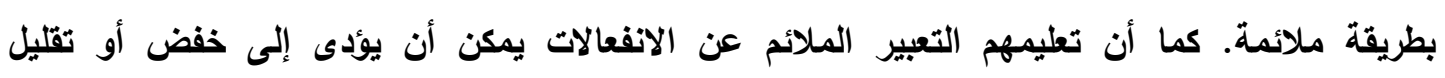

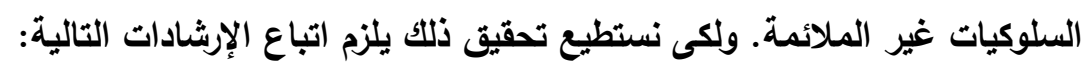

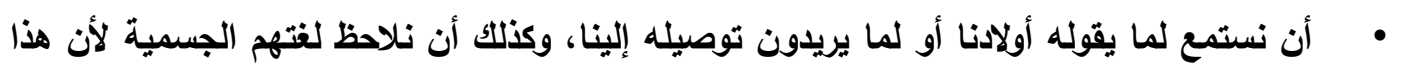

يزيد من فهمنا لما يريدون قوله.

\footnotetext{
1 - Eternal children .

2 - Sexual beings . 
• يجب تثجيع الأبناء على أن يظهروا انفعالاتهم تجاه الآخرين بطرق ملائمة، وأن نعلمه الطرق المقبولة لمقابلة أناس جدد، فلقاء أناس جدد لا نعرفهم جيداً يكون بالترحاب بهم بالقول أو بالسلام باليد

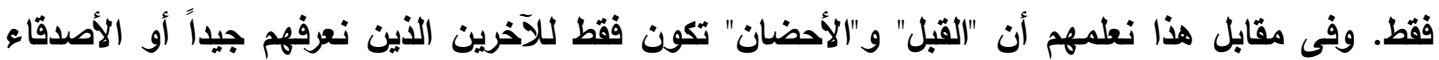
القريبين. • إذا تصرف الطقل تصرفاً خاطئاً يجب أن نتكلم معه عن هذا الخطأ، وعن الطرق الأفضل للتعبير عن

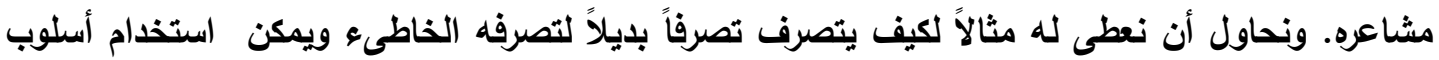
"أداء الدور" أيضاً.

• قلدم المواقف الطبيعية معظم البيئة الفعالة لتعليم الطرق الملائمة للتعبير عن الانفعالات.

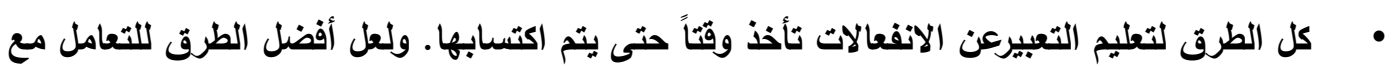

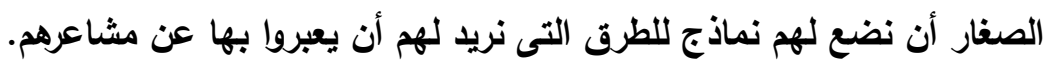

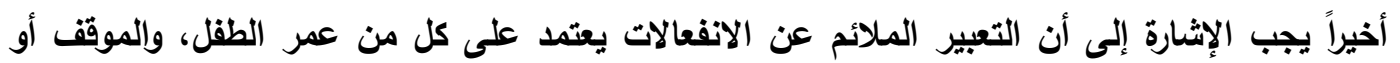

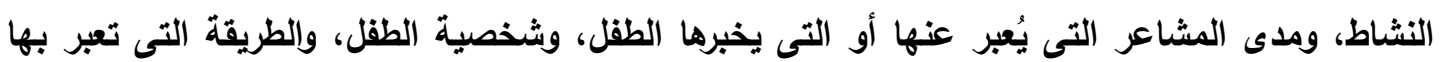
الأسرة ككل عن الانفعالات. تقدير الذات: إن تقدير الذات ببساطة اعتقادتنا ومشاعرنا تجاه أنفسنا، أو هو إدراك ذواتنا كأفراد. وهذا يتضمن كيف

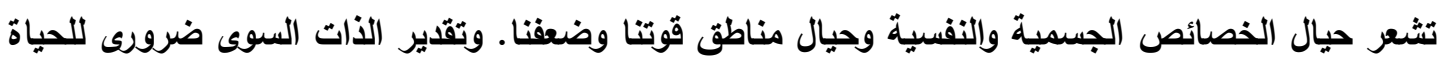

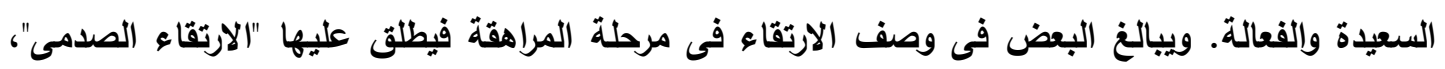

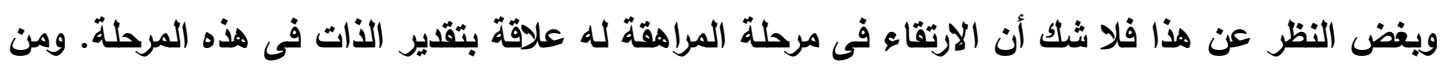

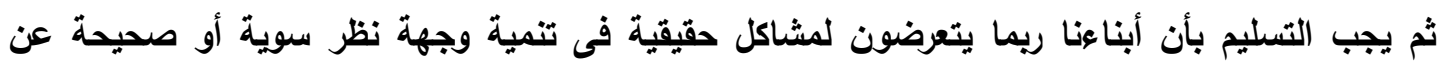

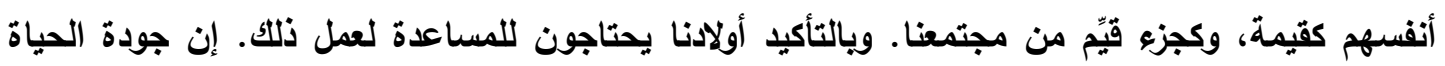

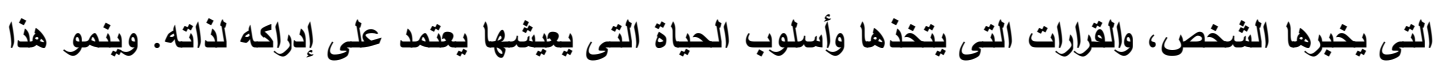

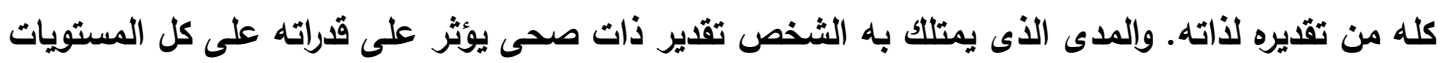

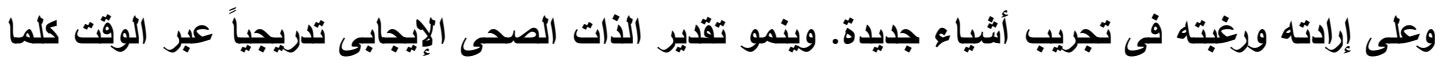
نمى الشخص. كما أن تقديرنا لذواتنا هو انعكاس لكيف نشعر حيال أنفسنا، وتفسيرنا لكيف يرانا

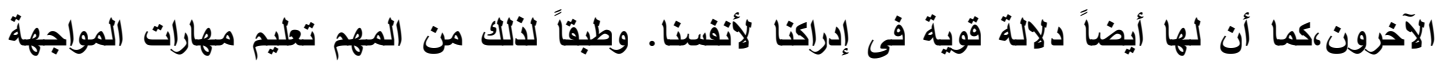

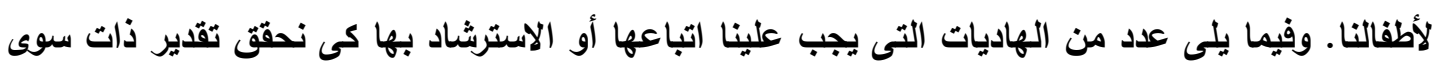
لاى أطفالنا:

• دعم ملائم لقدرات الطقل ومناطق القوة لايه، ويجب التأكد من استخدام لغة ملائمة للمرحلة العمرية

$$
\text { التى يمر بها ولمستوى الفهم لايه. }
$$

• تقديم فرص لتجريب أثياء جديدة للطقل، وهذا سيوسع من قوتهم الموجودة بالفعل، أو سيبرز قواهم التى ريما لا نعلمها أو لا يعلمها الطقل نفسه.

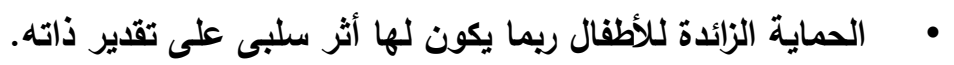

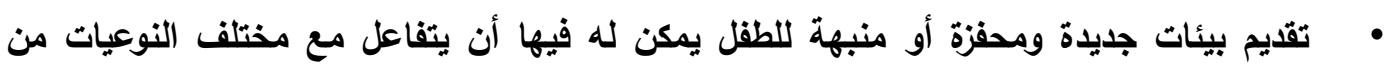
الأثخاص. وهذا سيساعده على تنمية الثعور بالذات، ويقدم له نماذج من السلوك الذى يمكن له أن يجريه لهنه

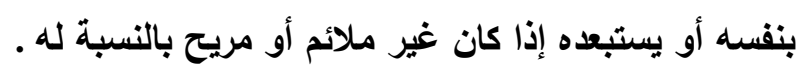


• التحدث بشكل منفتح مع أولادنا بعد مرورهم بخبرة جديدة، أو مقابلة أثخاص جدد أو محاولتهج

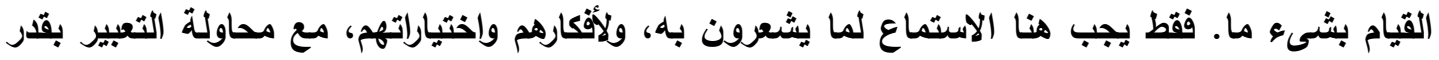
الإمكان عن تقديرنا لها مما يزيد من احتمال تقديرهم لذواتهم. • تشجيع الأطفال على أن يتحملوا مسئولياتهم فى بيئة المنزل. وهذا سيشجعهم على الاستقلال، وكذلك سيتيح لهم الحصول على الدعم واحترام الذات.

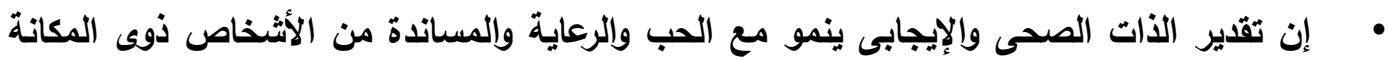
الخاصة لاينا لأنتا نواجه خبرات الحياة معاً.

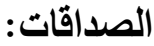

لا شكك أن وجود الأصدقاء هام لنمو المهارات الاجتماعية ومهارات التواصل، وهى جزء مكمل لارتقاء الهوية الذاتية التى تؤدى دوراً هاماً فى تقدير الذات لاى الثخص. ويالإضافة إلى ذلك، تقدم الصداقة الفرصة للتفاعل مع الآخرين خارج الأسرة، ومن خلالها ينمو الاحساس بالاهتمام والرعاية، والثقة والاحترام تجاه الآخرين. وريما يكون لدى الطفل فرصاً محدودة تتاح له كى يقيم صداقات مع جماعة الأهن الأقران. وريما تكون له شبكة علاقات اجتماعية صغيرة مكونة من أفراد الأسرة وأصدقاء الأسرة فقط، وهؤلاء الأشخاص

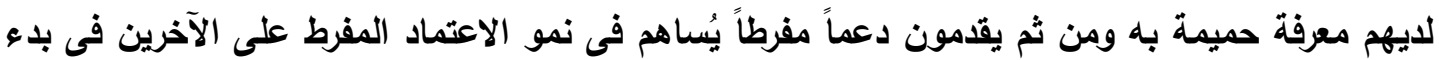

محادثة أو التفاعل بثكل عام. وهناك عدد من الطرق التى يمكن بها مساعدة أولادنا لعمل صداقات منها:

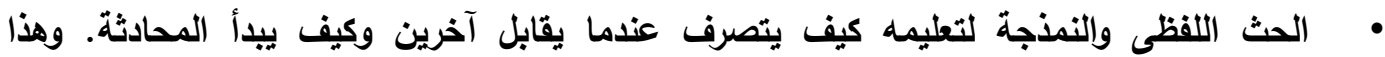

$$
\text { سيساعد فى تنمية السلوك الملائم. }
$$

• مساعدة الطفل على أن يميز بين السلوكيات الملائمة فى المواقف الدقيقية كنقيض لما يشاهدونه

$$
\text { فى وسائل الإعلام. }
$$

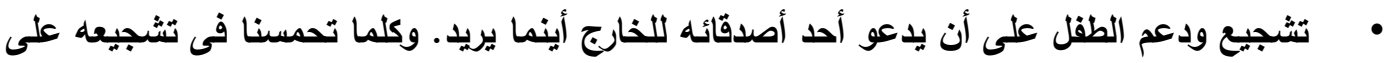

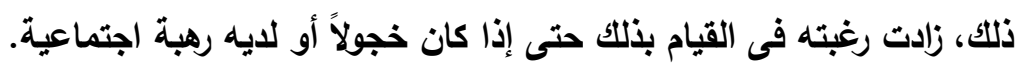

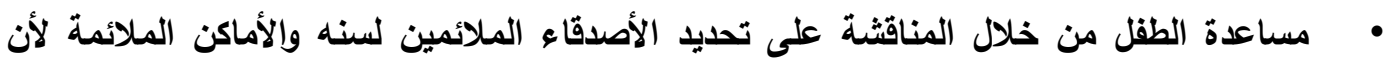

يذهب إليها معهم.

• تعليم الطقل حقوقه ومسئولياته فى الصداقة. ويمكن تحقيق هذا من خلال مناقشة حقوقه ومسئولياته عندما يخبر مشكلات مع أصدقائه. لغة التواصل: إن السؤال الصعب لاى الآباء هو ما هى اللغة المناسبة لاستخدامها عندما نناقش التربية الجنسية مع الطفل؟. لأن معظم الآباء لايهم خبرة ضئيلة فى الكلام عن الجنس، فهم لايهم خلط في كيف نشرح بمفاهيم علمية وسليمة لأبنائنا المراهقين أموراً تخص التربية الجنسية. كذلك كثير من المفاهيم الحيوية العضوية التى لدى الآباء لن تكون ملائمة للأطفال الصغار أو لاى ذوى الإعاقات أو صعويات التعلم، ويُضاف إلى من الته

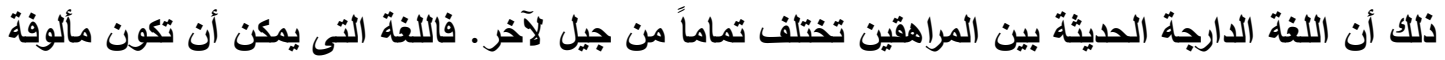

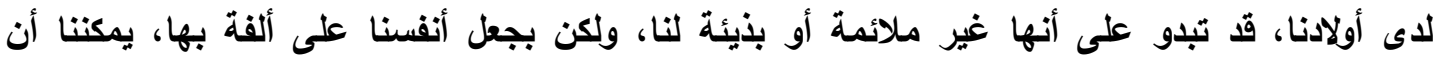

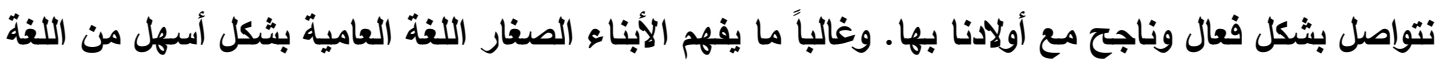
العلمية، لأنها اللغة التى يستخدمونها مع زملائهم وهى التى يسمعونها فى بعض وسائل الإعلام. ويغض

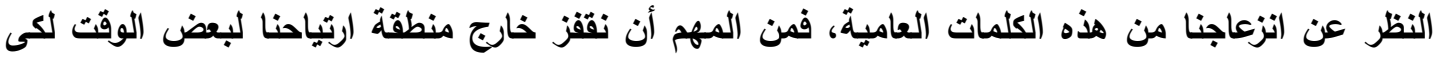


نفيد أولادنا فى موضوع التربية الجنسية. نحن نحتاج فى الحقيقة أن نربى أنفسنا فى نفس الوقت. والطريقة

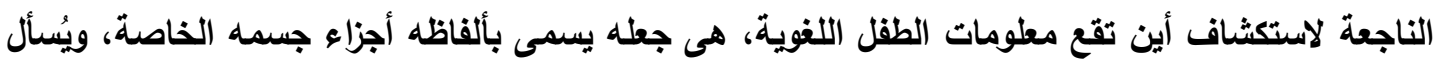

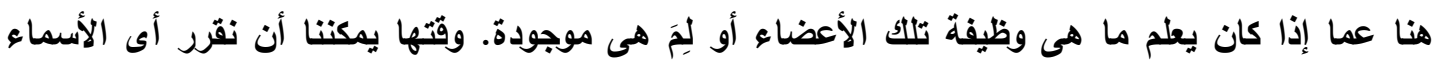
سوف نستخدمها فى تعليمه. وهذا الإجراء لا يساعدنا فقط فى معرفة اللغة التى سنستخدمهاءولكن يعطينا أيضاً فكرة عن دقة معلوماته فى هذا الثأن. ولحسن الحظ فإن هذاء الانزعاج المبئيى الذى قـ يبديه الأبوان سيتبخر بعدما يصبحون أكثر ثقة فى مناقثة الأمور الجنسية. كنلك من المهم أن نعترف بحدودنا وقراتنا

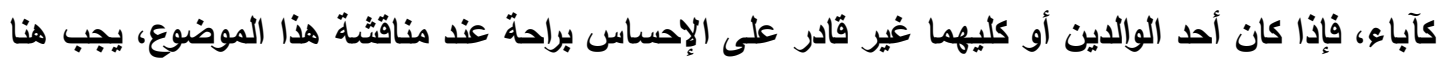

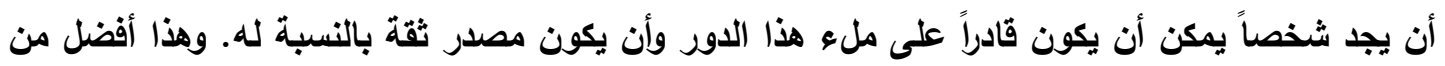

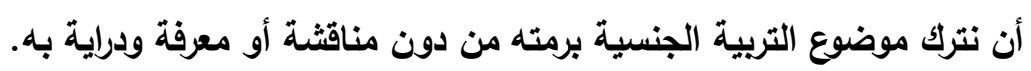

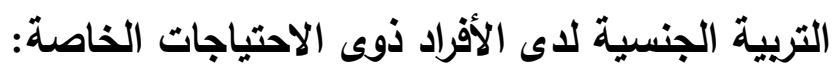

أوجزت كونهوفن (Couwenhoven,2007) العوامل المسئولة عن تباين التربية الجنسية لاى المراهقين ذوى الإعاقات الأهنية عنه لاى الأسوياء فى أريعة عوامل تشمل نقص المعلومات الصحيحة المتوفرة لهم،

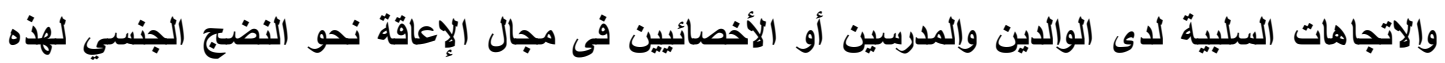
الفئة، والتأخر فى تدريس معلومات جنسية لهم أو إرجاء ذلك أو إلغائه نهائياً، والفرص القليلة للتفاعل

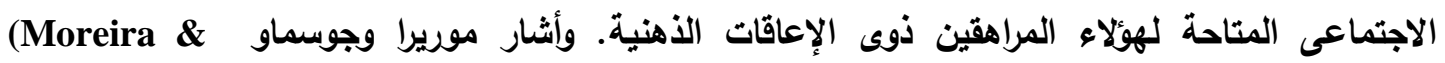
Gusmao, 2002) الاجتماعى' قد تمثل معوقات تحول دون النمو والارتقاء الجنسى السوى لدى المراهقين ذوى متلازمة داون

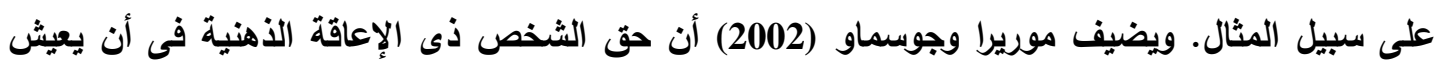

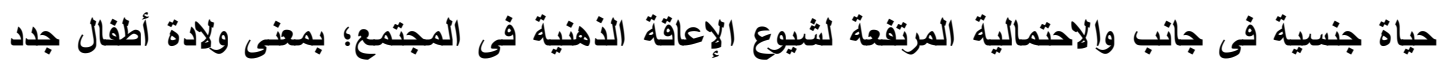

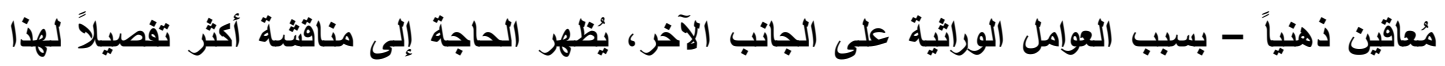

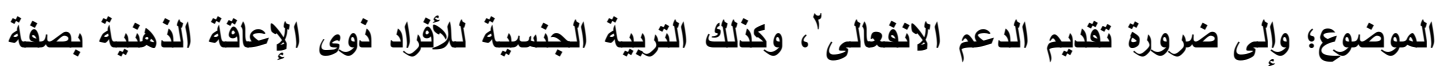
عامة شأنهم شأن الأطفال العاديين. دور الآباء فى التربية الجنسية: الإطفال العادين يمكن إجمال هذا الدور فى الآتى: أ-إدرالك الجنسية كملمح صحى وإيجابى فى الثخص.

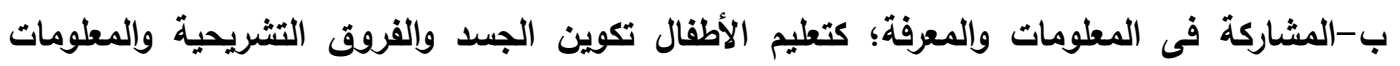
المرتبطة بفترة البلوغ والاحتلام. ج-توصيل القيم المجتمعية والثقافية؛ كأدوار الأسرة وأساليب الحياة ونظم الزواج والطلاق والانجاب، والأدوار المرتبطة بالنوع (ذكر -أنثى).

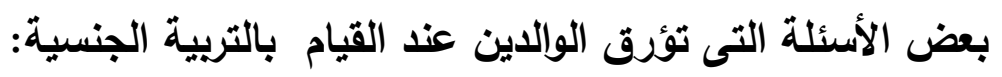

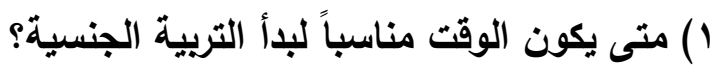
إن التربية الجنسية تكون فعالة أكثر عندما تبدأ فى سن مبكرة، ويثكل مستمر خلال المراهقة، فتعليم

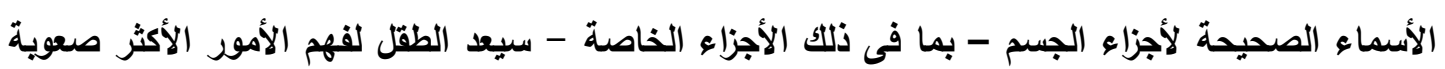

\footnotetext{
1 - Social prejudice.

2 - Emotional support.
} 
فيما بعد. وهذا لا يُقام له فقط مثالاً للغة مناقشة الأمور الجنسية معنا، ولكن أيضاً هى بمثابة إذن منا بأن يناقثها معنا. فنحن بذلك نزيد من قوة أطفالنا لاتخاذ قرارات ووضع تصورات عن جسمهم وعن إدراتهم لله.

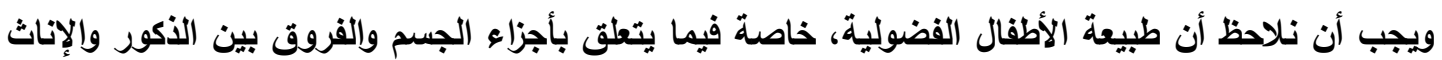
- إذا لم تثبع، فإنهم سيلجأون إثباعها بالتجريب خارج إطار الأسرة. r هناك قلق عام لدى كثير من الآباء والمربين، لأن الأطفال لايهم ميل لأخذ أكبر قدر من المعرفة التى

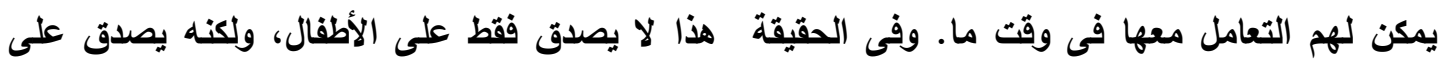

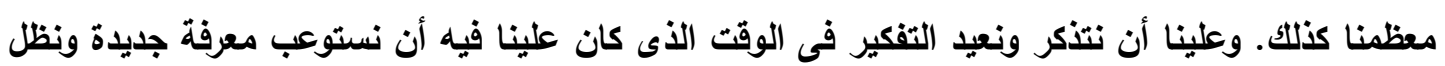

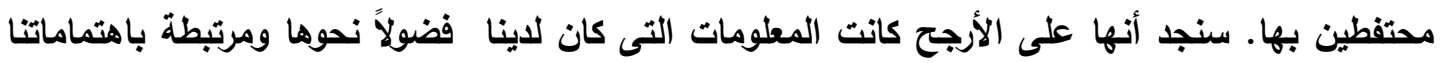

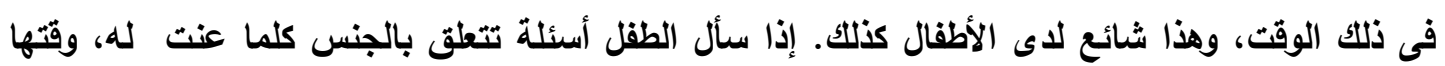
سيصبح من السهل أكثر أن نستجيب للسؤال بلغة سهلة ويسيطة. ومن المفيد أن نفكر فى الماضى أثناء

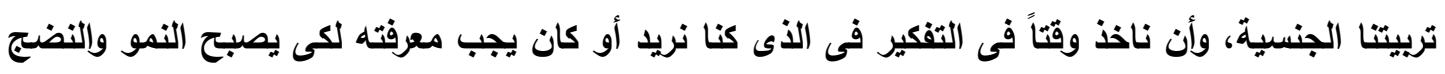

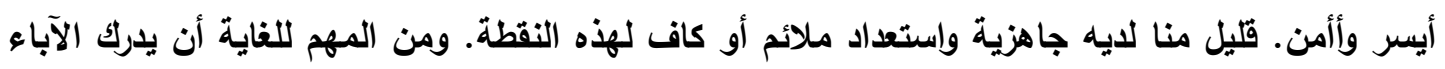

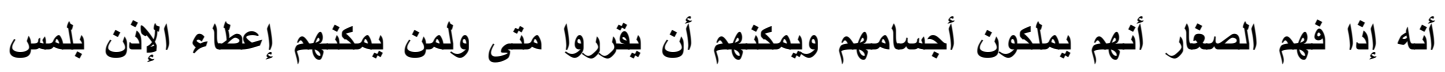

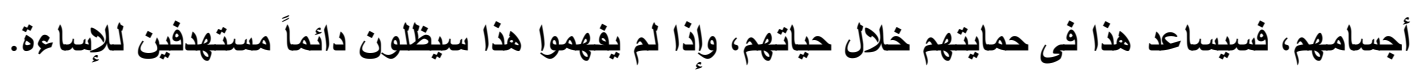

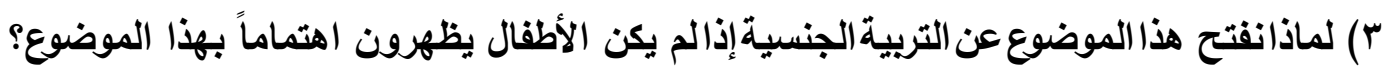

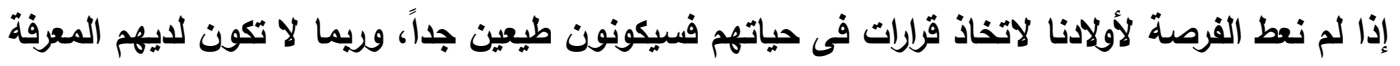

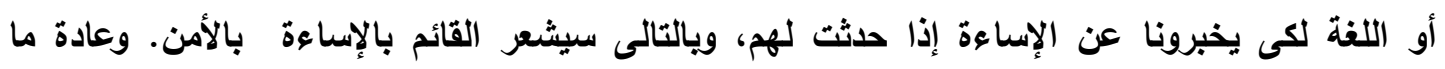

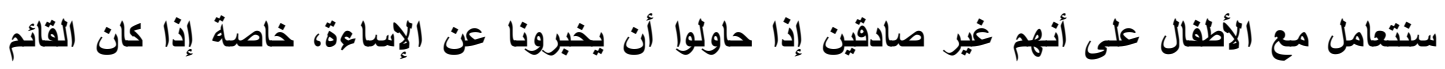

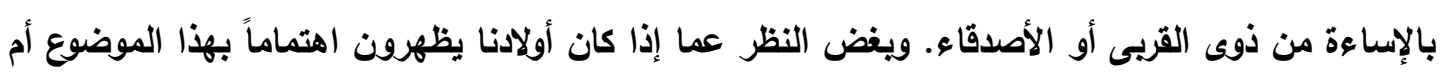

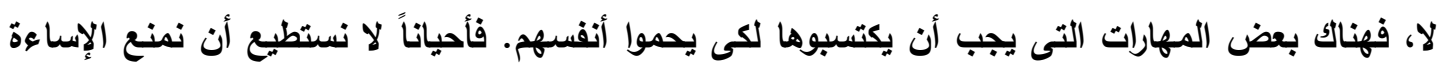

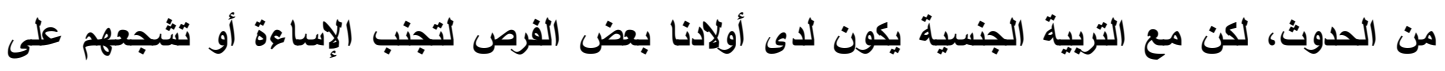
التواصل معنا كى نعلم عنها ونسعى إلى مساعدتهم إذا حلث شعى لثع ما.

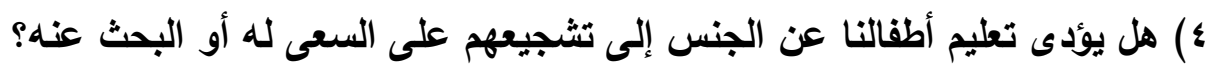

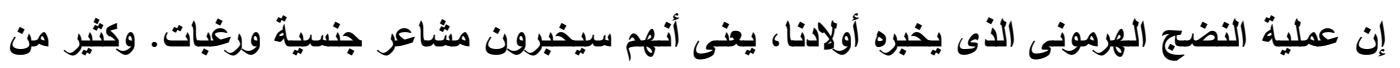
الآباء يتمنون أن لا يكون أولادهم ليس بسبب أنهم ينكرون عليهم أن يكون لأبنائهم حياة طبيعية ومكتملة،

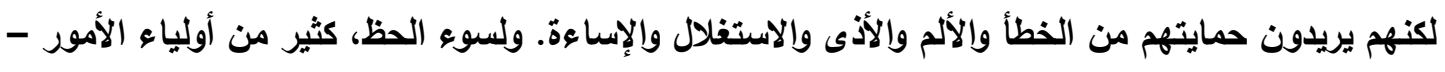

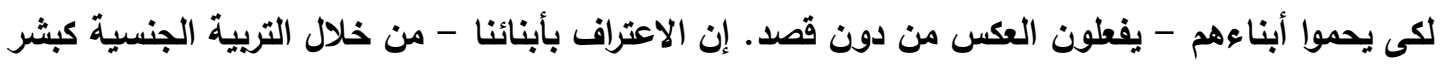
لايهم دوافع جنسية، يعطى الإذن لهم لأن يخبروا مشاعرهم، وهم بهذه الطريقة يكونون أقل احتمالاً لأن

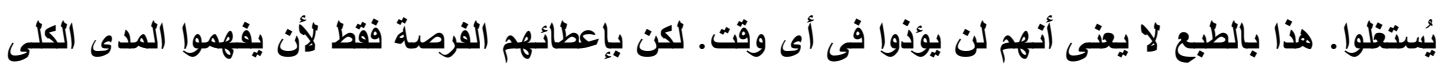

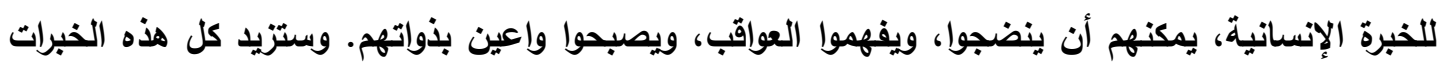

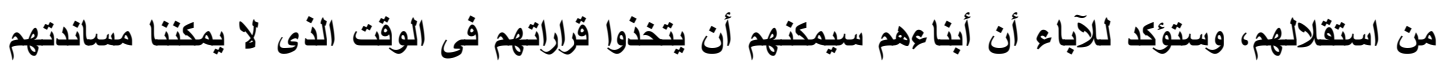


•) ماذا يفعل الوالدان إذا شعروا أنهم لن يستطيعوا التحدث مع أولادهم عن الجنس؟ كثير من الآباء ليس لايهم تربية ملائمة أو كافية عن الجنس. ويالتالى ليس لديهم أى خبرة فى الكلام

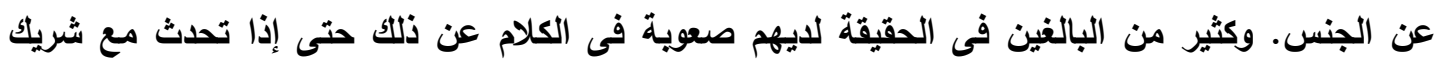
حياته. فقط فى البداية علينا أن نقفز خارج منطقة عدم الارتياح. ويحتاج الآباء بالفعل لأن يكونوا المربين الأوائل للجنس بالنسبة لأولادهم، خاصة إذا كانوا ذوى احتياجات خاصة. وفى الحقيقة لا يمكنا الاعتماد على المدارس لتقديم كل التربية الجنسية للطقل أو للمراهق. فالتربية الجنسية فى المدارس لإسئل لا تتعدى كون المدرس يُعلمهُم بعد الأسس الفسيولوجية لها من خلال دروس علم الأحياء. ويصارع المدرسون غالباً عدم الجئه

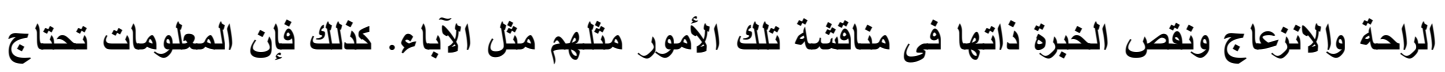

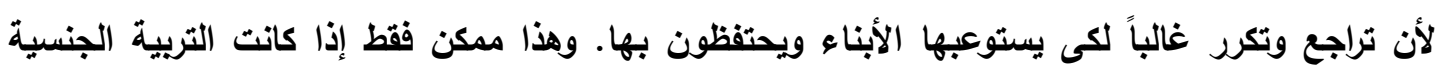

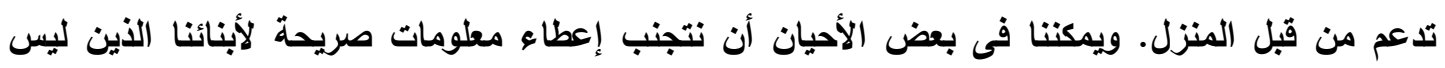
لديهم إعاقات، حيث يمكنتا أن نحيلهم إلى مصادرللمعلومات من خلال الكتب والمجلات العلمية، وأن نتاقش التش

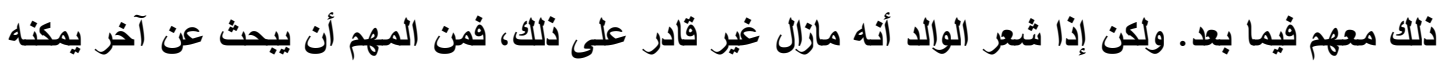

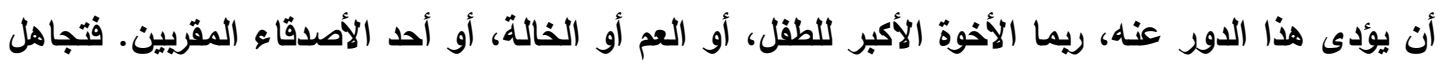
الأمر لن يحل المشكلة ويجعلها تذهب بعيداً.

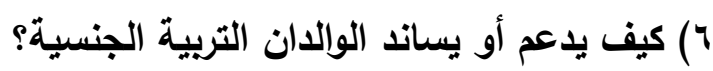

فيما يلى الخطوات التى يجب على الوالدين القيام بها لاعم ومساندة التربية الجنسية:

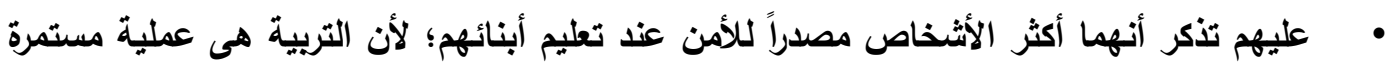

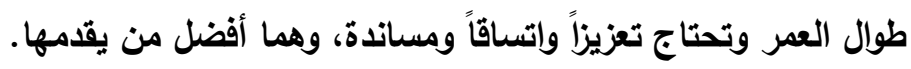

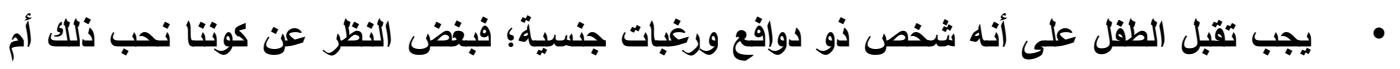

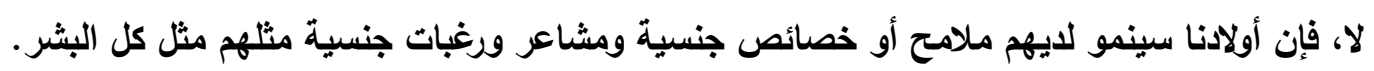

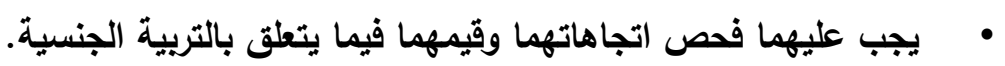

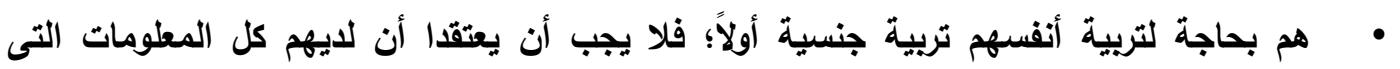
يحتاجونها. فثقتهما ستزيد فى توصيل المطلومات للطقل إذا كانت المطلومات دقيقة وملائمة.

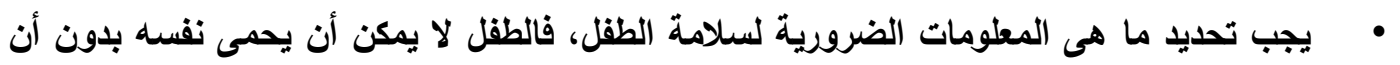

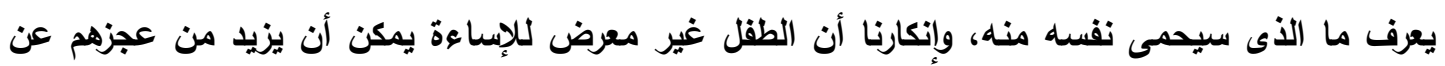
السعى لطلب المساعدة إذا احتاجوها. • يجب تصديد ما هى المعلومات الضرورية لأولادنا لكى يحصلوا على خبرات جنسية إيجابية. إذا

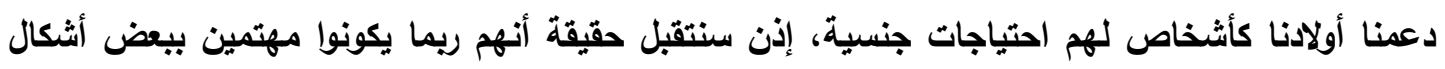

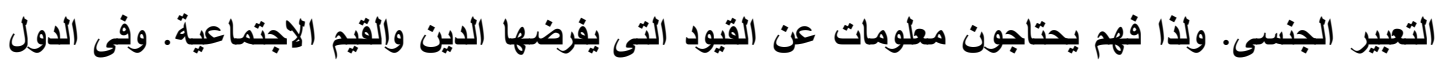
الغربية يهتمون بإعطاء معلومات عن موضوعات معينة مثل اللمس الملائم، والجنس الآمن، والإساءة

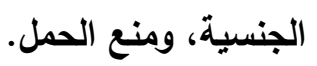
• يجب المحافظة على الصلة مع معلمى الطفل ودعم ومساندة برامج المدرسة فى المنزل. فأكثر أساليب التربية فعالية هى التى تتضمن كل ملامح حياة الثخص. ويجب أن نكون على دراية بالموضوعات

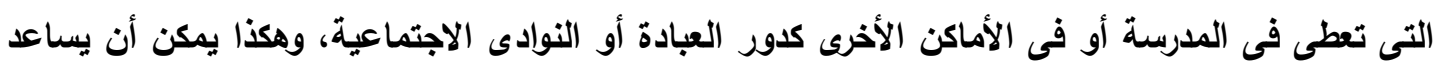
المنزل فى تدعيم المعلومات التى يكتسبها الأبناء. 
• استخدم التكرار باستمرار. فمن غير الواقعى أن نتوقع أن أبناءنا سيكونون قادرين على استيعاب

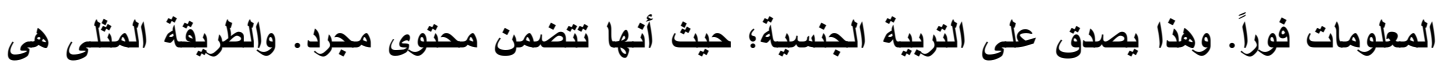
إحداث تكامل للتربية أو تضمين التربية فى حياتنا اليومية.

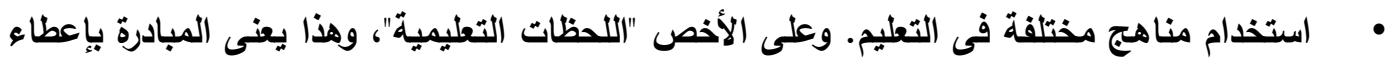

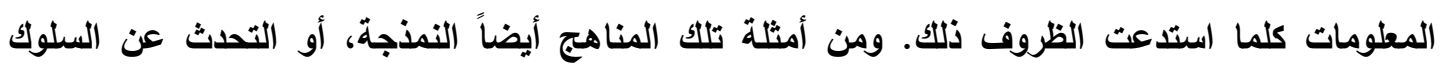

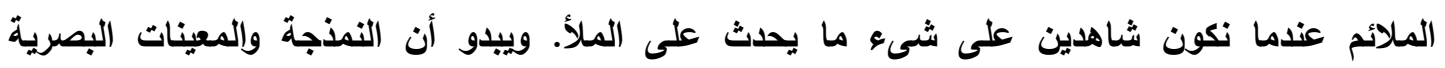

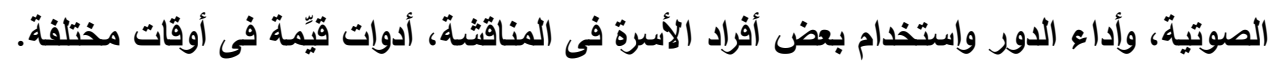

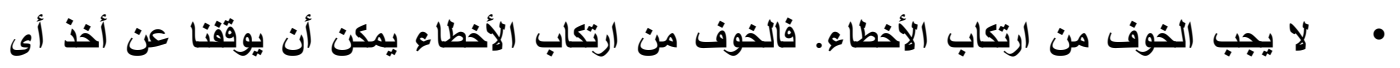

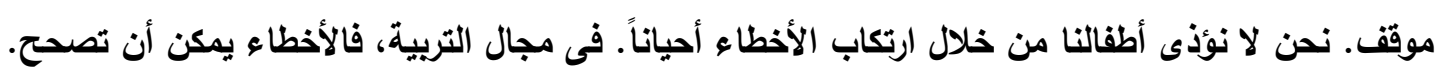

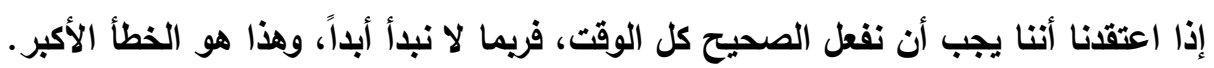

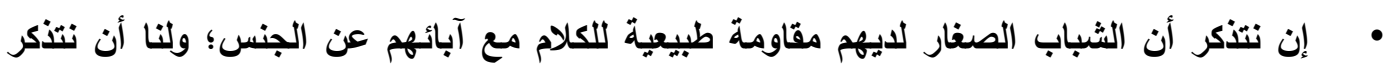

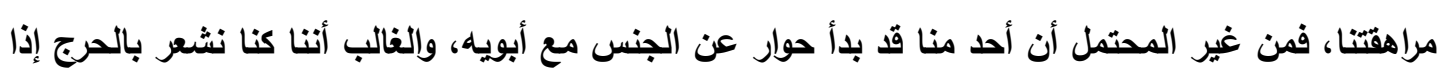

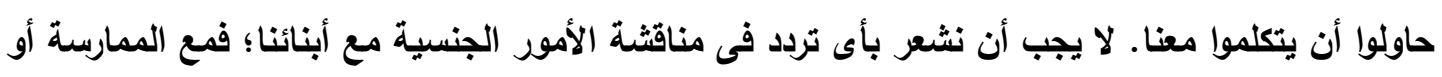

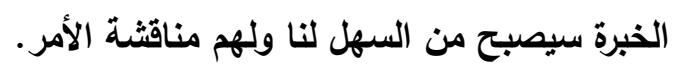

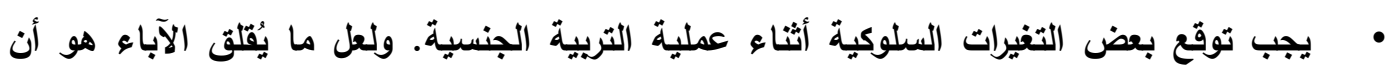

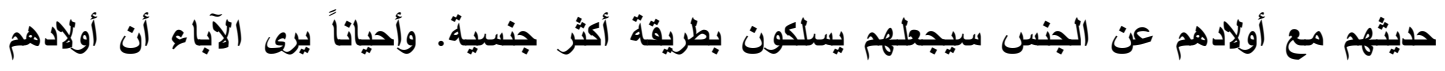

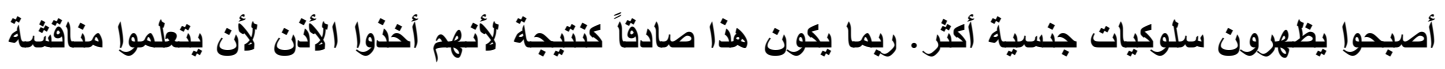

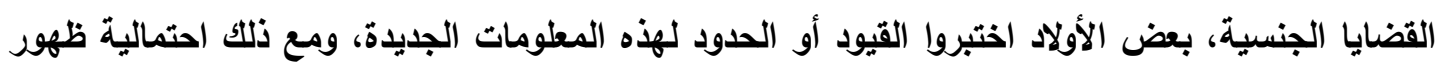

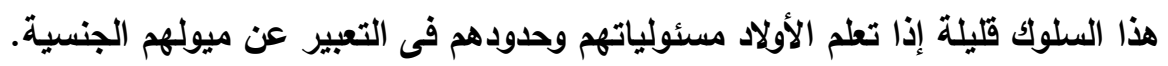

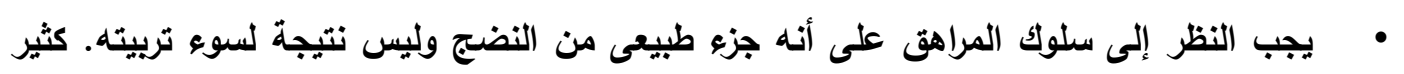

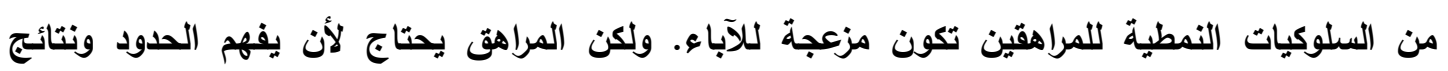

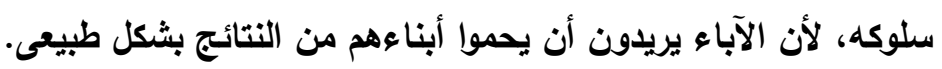

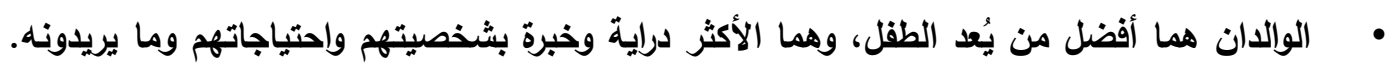

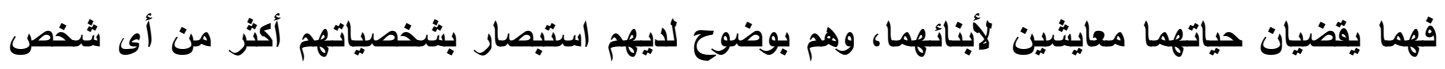

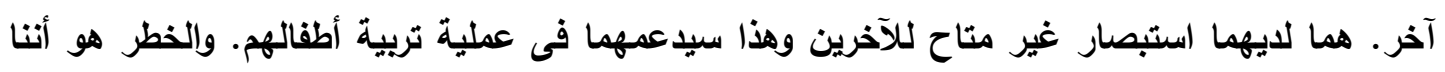

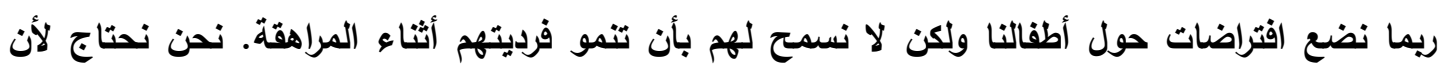

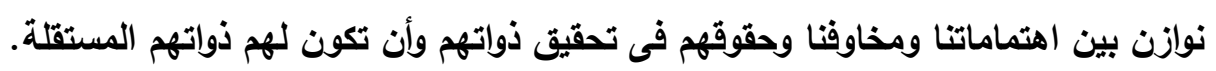

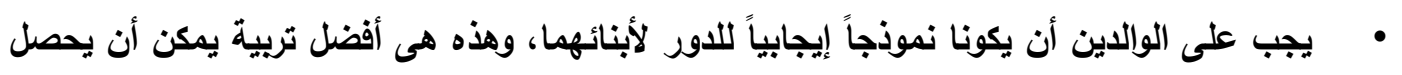

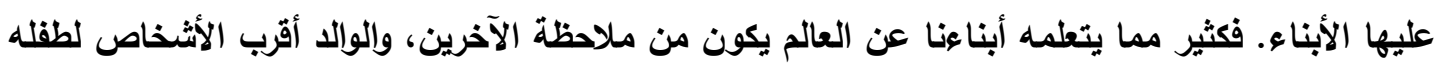

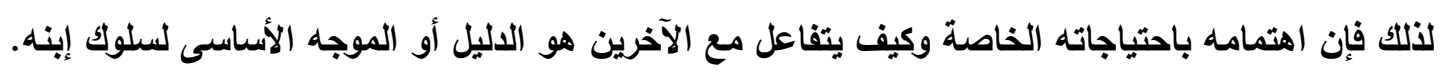

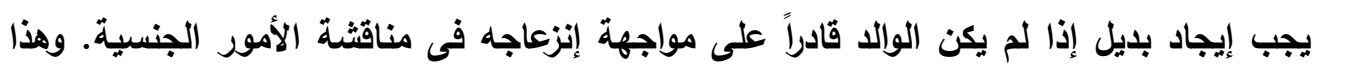

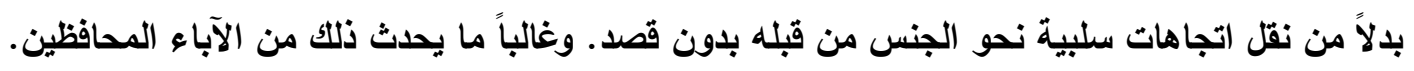

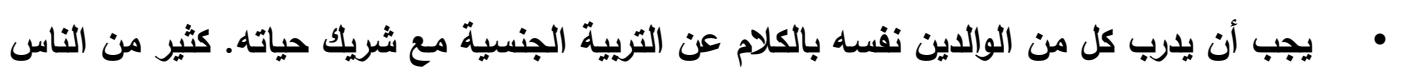

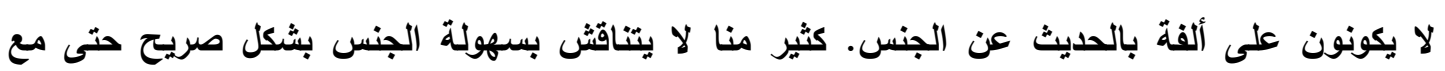

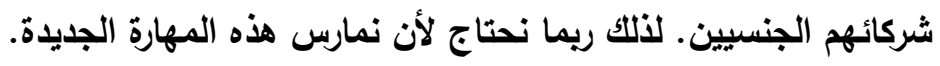


• يجب إعطاء الأبناء أكثر الفرص المتاحة كلما أمكن لاتخاذ قرارات تخص حياتهم الخاصة. فقط من خلال ذلك يمكن لهم أن يدركوا ذواتهم على أنهم مستقلين، ومشاركين ذوى قيمة فى الحياة. وهذا سيُحث

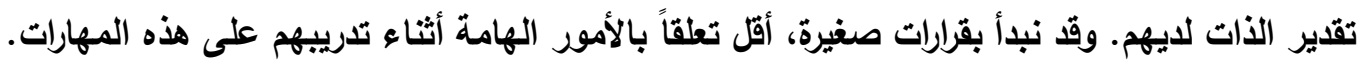

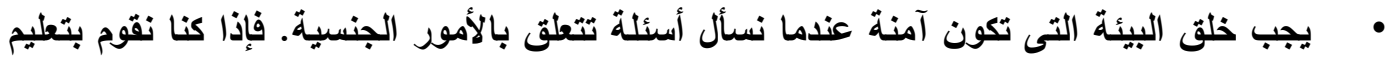

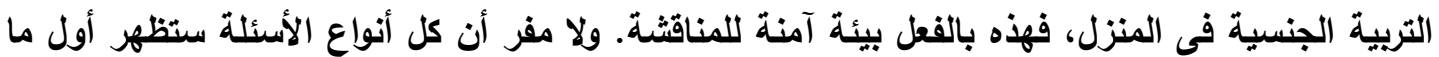
يُقتح هذا الموضوع. ومن خلال معالجة هذه المسائل بغض النظر عن محتواها سنكون قادرين على تصحيح أى معلومات مظلوطة لاى الأبناء. وفى الوقت نفسه سنعطى لهم فكرة أفضل لكيف يمكن أن تكتمل التربية وأيضاً سيحث ذلك التواصل معهم. • يجب أن نسمع للأطفال بأن يتعلموا من أخطائهم من خلال مساعدتهم بالتعلم من خلال الخطأ بدلاً

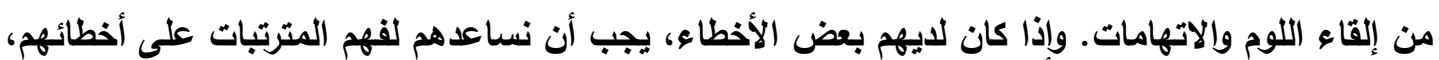
وكيف يتجنبونها فى المستقبل. وهذه هى أفضل طريقة للتعلم والنمو. • يجب قبول فكرة أن رغبات الأبناء هى نفسها التى لدى كلى ولى واحد منا؛ مثل الرفقة والعاطقة والألفة الحميمية. إن قبولنا لهذا سيمكنتا من تشجيع الخبرات التى تدعمه للوصول بإمكاناتهم لتحقيق رشد سوى

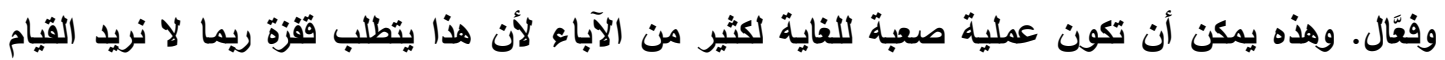

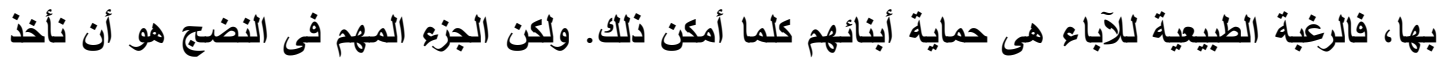

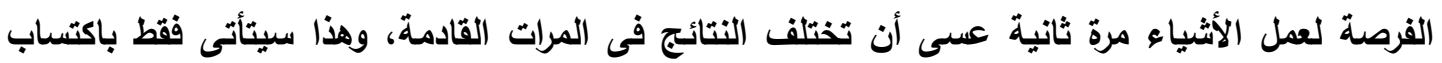

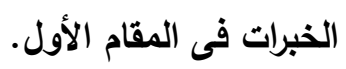

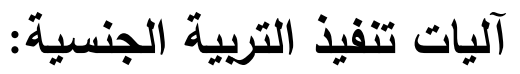
تبلور الإجابة عن الأسئلة الأربعة التالية آليات تنفيذ التربية الجنسية:

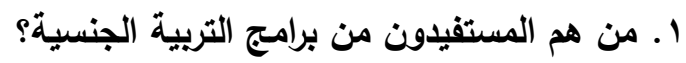

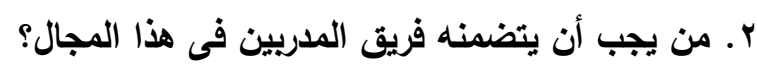

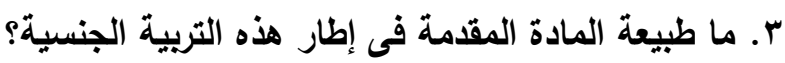
ء. ماهى خطط التدريب التى يمكن استخدامها مع مختلف المستويات من القدرات العقلية، وكذلك التهاه

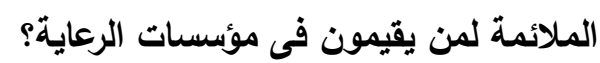

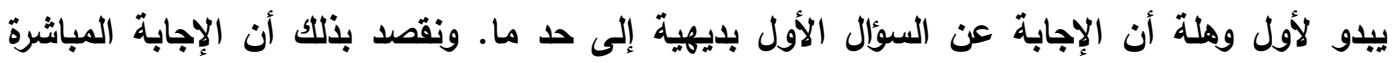

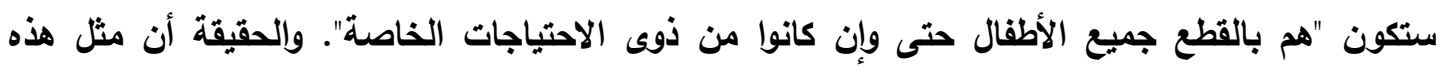

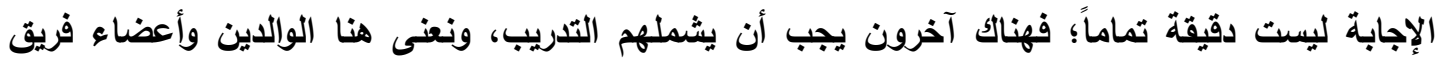

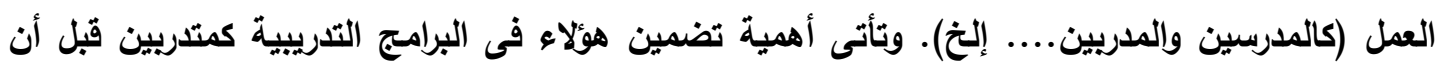
يصبحوا مدربين هو وجود كثير من الاتجاهات السلبية، ونقص المعرفة الجنسية لدى هؤلاء المنوط بهم تربية الأطفال جنسياً. وتُعدُ كل من التربية الجنسية واتجاهات الوالدين وأعضاء فريق العمل فى المدرسة، وفى مجال رعاية

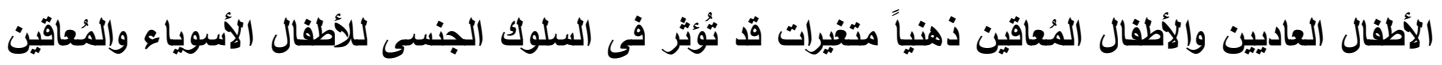
ذهياً. فنقص المطلومات الجنسية - ويصفة خاصة المطلومات عن السلوك الجنسى الملائم - لاى الوالدين، وكنلك لاى أعضاء فريق العمل قد يُعوّق النضج الجنسى الجيد لاى هؤلاء الأطفاء 
ولذا فقد أشار جونسون (Johnson, 1973) فى إطار عرضه لخصائص كل من المعلم والمادة المتعلمة

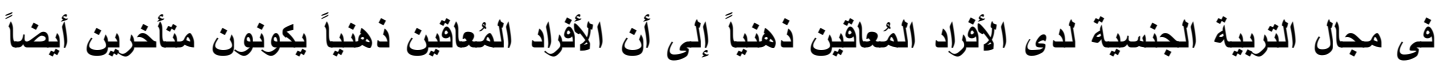

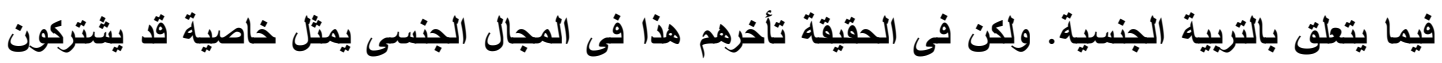

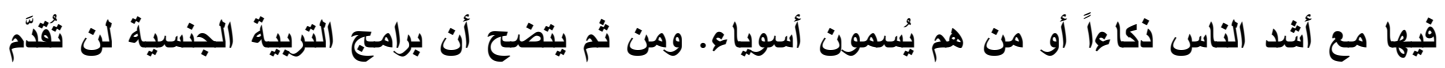

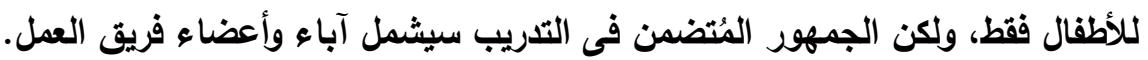

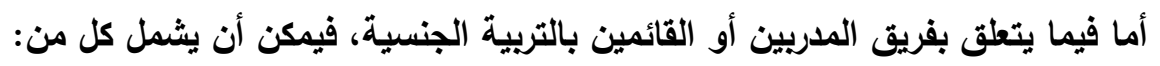

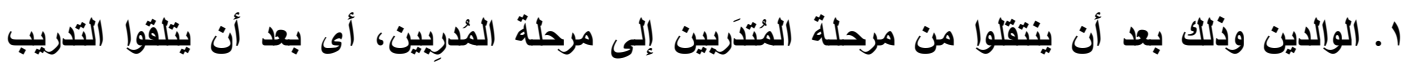
وتغيير الاتجاهات السلبية والمعارف الخاطئة. r. أعضاء فريق العمل فى المدرسة وفى مجال رعاية الأفراد ذوى الاحتياجات الخاصة؛ كالمدرسين والمشرفين والممرضين والمدربين والاختصاصيين الاجتماعيين.... إلخ. فئ.

$$
\text { r. الأختصاصي النفسى الإكلينيكى المَدَرَب. }
$$

ـ. رجل الدين، لَِّ يمكن أن يقدمه من معلومات دينية وتوصيات بتدريبات تتست مـع الدين الإسلامى

$$
\text { الحنيف وكذلك مع الايانة المسيحية. }
$$

هـ الأطباء بما لايهم من قدرة على شرح الجوانب الفسيولوجية والتشريحية.

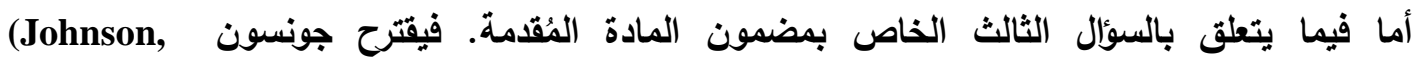
1981:reported in Haight \& Fachting, 1986)

$$
\begin{aligned}
& \text { حول: } \\
& 7 \text { ـ الدور الجنسى والمسئوليات' . }
\end{aligned}
$$

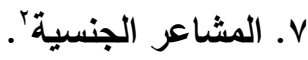

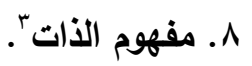

$$
\begin{aligned}
& 9 \text {. } 9 . \\
& \text { • } 1 \text { ـ مشاعر المودة والاتصال. } \\
& \text { 11 الرومانسية. }
\end{aligned}
$$

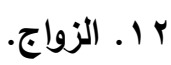

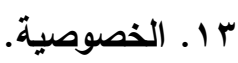

$$
\begin{aligned}
& \text { ـ ا ـ الاعتبار والتقدير؛ } \\
& \text { ه } 1 \text { ـ سفاح القُربى أو غشيان المحارم. } \\
& \text { 19 الإساءة الجنسية. } \\
& \text { IV }
\end{aligned}
$$

11. موضوعات فسيولوجية تقليدية متعلقة بالجنس (فسيولوجيا الجنس).

ويؤكد والكر -هيرش (Walker-Hirsch, 2002) دور ستة مكونات رئيسة للتربية الجنسية يمكنها أن

$$
\text { تلدعم نمو الصحة الجنسية، وتثثمل: }
$$

\footnotetext{
1 - Sex role and responsibilities .

2 - Sexual feelings .

3 - Self-concept .

${ }^{4}$ - Respect
} 


$$
\begin{aligned}
& \text { 1- الرعاية الذاتية البالغة. } \\
& \text { r - التشريح الفسيولوجى لموضوع الجنس. } \\
& \text { r- بقاير الذات واستقلالها. } \\
& \text { ؛ - - بناء العلاقات الاجتماعية. } \\
& \text { ه- المهارات الاجتماعية. } \\
& \text { צ- - الحقوق الجنسية والمسؤليات. }
\end{aligned}
$$

ويفصل كرافت وكرافت (Craft \& Craft, 1985) بين مضمون المادة المقدمة لكل من المُعاقين إعاقة ذهنية متوسطة والمادة المقدمة لذوى الإعاقة الذهنية البسيطة. ويرى الباحثان أن مثل هذه البرامج تؤدى دوراً فى وقاية هؤلاء الأفراد من الاستغلال الجنسى، كما تُعينهم على فهم النضج الجنسى لديهم؛ حيث تثمل برامج التربية الخاصة بذوى الإعاقة الذهنية المتوسطة والثديدة:

1. الفروق بين الأكور والإناث (أى بين الجنسين).

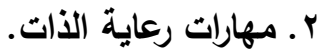

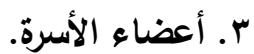

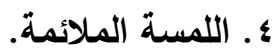

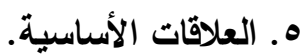

צ. التقاعل الاجتماعى ووسائله.

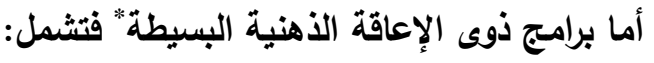

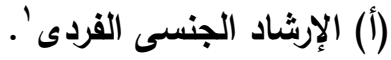

(ب) وفى المدرسة قد يتضمن البرنامج تدريباً للعلاقات الشخصية: الأردئ

1. التعرف على الأمزجة والمشاعر.

r مهارات التفاعل الاجتماعى.

r. ب. تكوين الصدقات والاحتفاظ بها.

ع ـ مهارة الرفض وهى أحد مهارات توكيد الذات.

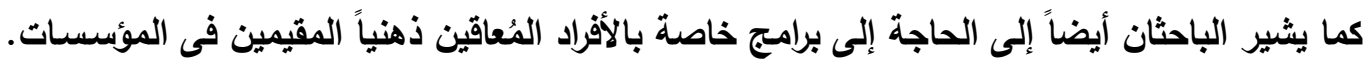
وقد أكد شواب (Schwab, 1992; 2001) ويوتثل (Pueschel,2001) أهمية أن تتضمن برامج التربية الجنسية تنمية مهارات توكيد الذات وغيرها من المهارات الاجتماعية كالوعى بالآخر واتخاذ القرار وتقبل

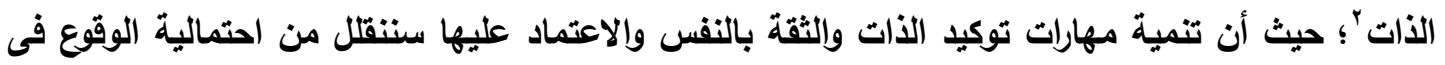
الاستغلال الجنسى. هذا بالإضافة - كما سبق وأن أثرنا - إلى المعلومات الصحيحة والحقائق عن الجنس والنضج الجنسى والرعاية الذاتية فى هذا المجال؛ مثل رعاية الإناث لأنفسهن أنثاء الدورة الثهرية (الجمعية

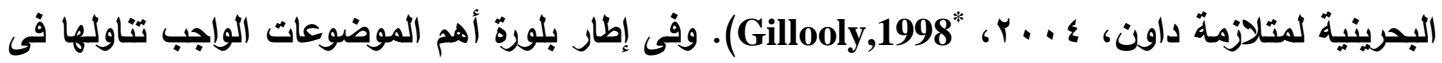
إطار التربية الجنسية أثشار كل من هكا-لكس ومين (Haka-Lkse \& Main, 1993) وجرانت (Grant,1995)

1 - Individual sexual counseling .

" يمكن تطبيقها أيضاً على الأطفال العاديين الأصغر عمراً.

2 - Self-acceptance.

" قام جيلولي (1998) تصويراً من خلال كتابه "قفيل أن تحدث الدورة لايها:تكلمى مع إبنتك عن الحيض"- عن كيف يمكن مساعدة الو الادين - والام بصفة خاصة. على إعداد بناتهن للبلو أن و الحيض. 


$$
\begin{aligned}
& \text { 1. مفهوم الأت الإيجابى. } \\
& \text { r. الاتصال والمودة والاقتراب الجسمى. الإئ. } \\
& \text { r. الاحتشام والخصوصية. } \\
& \text { ؛. ـ الاستمناء أو العادة السرية. } \\
& \text { ه. الأمن الثخصى. }
\end{aligned}
$$

إذا انتقلنا إلى خطط التدريب فسنجد أن خطة الدوائر المتحدة المركز التى قدمها ولكر -هيرش وتثامبجن

(Walker-Hirsch \& Champagne,1992;Walker-Hirsch,2002) المطروحة للتدريب وذلك بصفة خاصة لاى الأطفال الصغار والأطفال ذوى الاحتباجات الخاصة. ويُطلق أيضاً على هذه الخطة مُسمى "تموذج أو مخطط المسافة الجسمية والانفعالية" ". وهو عبارة عن مجموعة دوائر

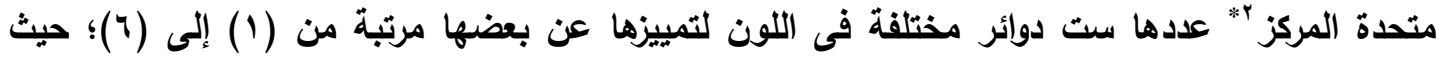
يُعطى الرقم (1) للائرة الأصغر القريبة من المركز. وتعكس كل دائرة فى تصميم الدوائر متحدة المركز هذا علاقة شخصية معينة ودرجة مقبولة من السلوكيات الجسمية المتسمة بالألفة أو العلاقة الحميمة كالتقبيل أو العناق، ويشغل الفرد مركز هذا التصميم. ويتعلم التلاميذ على سبيل المثال أن الغرياء يشظلون أو يقعون

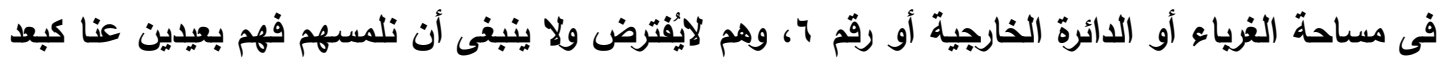
هذه الدائرة عن المركز الذى يقابل الثخص نفسه. أما العلاقات المتسمة بالرقة واللطف فموجودة في الائرة

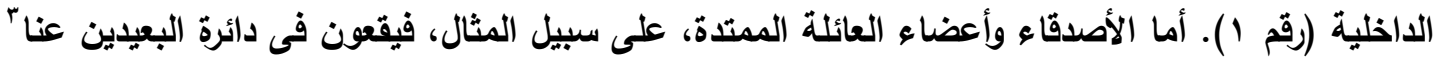
(الدائرة رقم ץ). ويتعلم التلاميذ هنا سلوكيات اللمس الملائمة لدرجة أو نوع علاقة المودة الموجودة فى كل

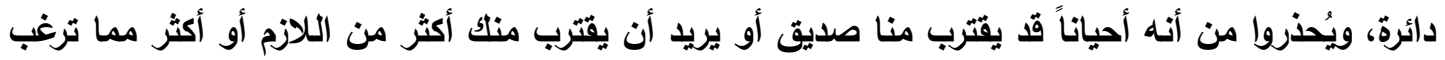

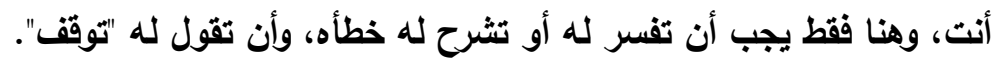
نخلص مما سبق إلى أن نموذج الدوائر متحدة المركز هو وسيلة لشرح قواعد العالم الاجتماعى" للأطفال بطريقة عيانية حيث يحول الفكرة المجردة للمسافة الثخصية وحدود العلاقات إلى مخططات بصرية عيانية

ويمكن أيضاً للأفراد المُعاقين إعاقة ذهية شديدة أو من لايهم تأخر لغوى أن يتعلموا من خلال نموذج

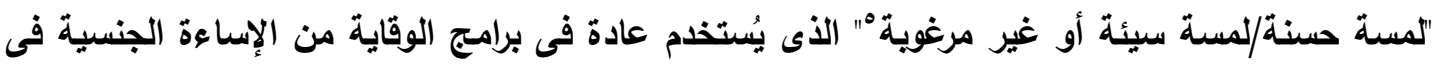

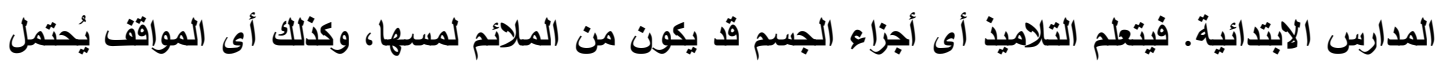

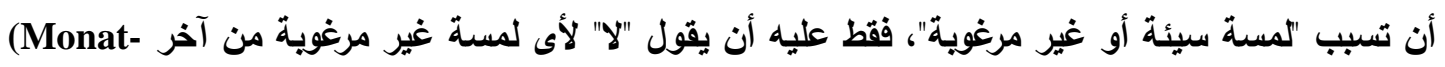
.Haller,1992; Haka-Lkse \& Mian,1993) وفى مقابل خطة الدوائر متحدة المركز ونموذج "لمسة حسنة/لمسة سيئة أو غير مرغوبة" قدمت ماى

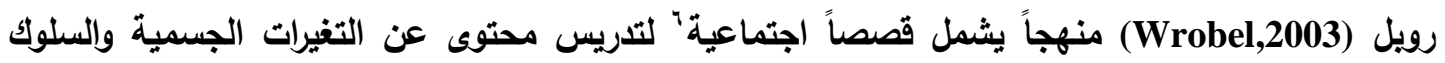
الجنسى الملائم وتثجيع الاستقلال فى العادات الصحية والنظافة والرعاية الذاتية بصفة خاصة لنئة للأطفال

\footnotetext{
1 - A paradigm of physical and emotional distance.

2 - A concentric design.

" يمكن مراجعة الثكل بالرجوع لولكر-هيرش وتشامبجن (1992) وولكر -هيرش (2002) حيث لم يتمكن الباحثان من وضع الثكل

3 - The 'far away' circle .

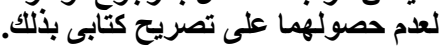

4 - The rules of social world.

5 - The 'good touch/bad touch' model .

6 - A social stories curriculum.
} 
التوحديين. ويُعدُ كتاب كُنهوفن (Couwenhoven,2007) مصدراً شاملاً وهاماً لأفضل طرق تدريس الأمور الجنسية، حيث يُقدِّم معلوماتٍ تطبيقية وأفكاراً للتدريس تغطى مدى واسعاً من القضايا والموضوعات الجنسية

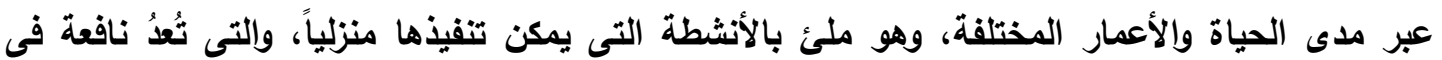
تدريس وتعليم موضوعات عن الجسم والخصوصية والعلاقات والوقاية من الاستغلال الجنسى والاغتصاب. كما تشمل ملاحق الكتاب رسوماً تفصيلية وواقعية يمكن استخدامها في التدريس. وقدَّم بِكر وبرايت مان (Baker \& Brightman, 2004) تصوراً أساسياً لكيفية تدريس مهارات رعاية الذات والتدريب على الحمام والاعتناء بالذات فى المنزل' وتعديل السلوكيات المتعارضة مع التعلم. وأخيراً طرح كل من ماكسيم (Maksym,1990) وشوير وهينجزيرجر (Shweir \& Hingsburger, 2000) ودرورى وهتشينسون ورايت (Drury, Hutchinson \& Wright, 2000) تصورات جيدة عن كيفية تنفيذ التربية الجنسية بالمنزل من قبل الوالدين. وعرضت لورا برمان (Berman,2013) لطبيعة المادة الواجب تقديمها عرضاً ارتقائياً على النحو التالى:

$$
\text { أ- من الميلاد وحتى نهاية العام الأول: }
$$

ضرورة تقديم معلومات عن أسماء ووظائف الأعضاء الجنسية من خلال أولاً استخدام الأسماء الصحيحة

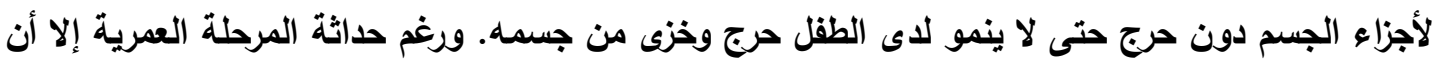
الفهم يسبق انتاج اللغة. ب- بداية من عامين إلى ثلاثة أعوام وحتى نهاية العام الدراسى الأول: هذا هو الوقت الذى يبدأ فيه الطقل طرح أسئلة عن جسمه وعن أجسام المحيطين بهايه وريما يبدأ

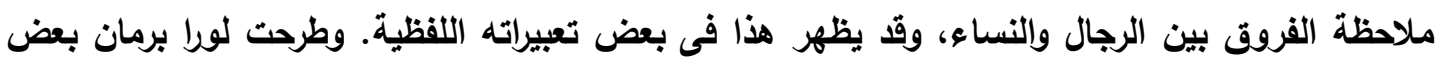
أسس التربية الجنسية فى هذه المرحلة:

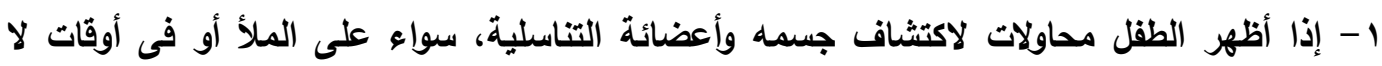
تكون ملائمة. يجب أن يُشرح له ببساطة أن أعضاءه التناسلية - القضيب أو المهيل - هى أعضاءهاه الخاصة، ولذلك لمسهم لا يجب أن يكون إلا فى خصوصية وليس على المهل الملأ.

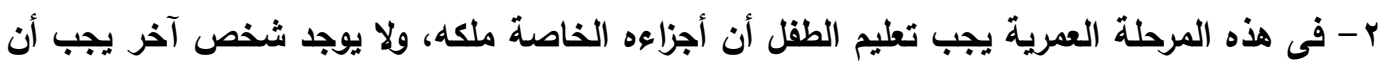

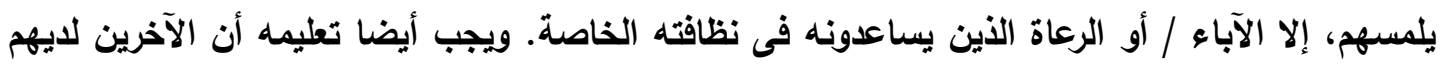

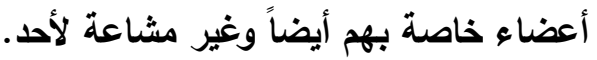

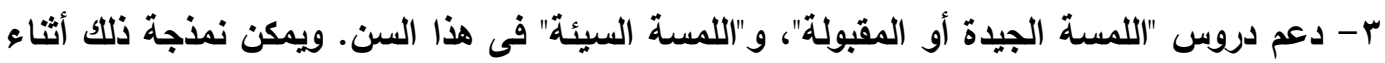
لعب الطقل مع إخوته أو أصدقائه بتدريبه على توكيد ذاته ورفض أى لمسة اونة غير مقبولة. ج- خلال الصفين الاراسيين الثانى إلى الرابع: قـ تظهر فى هذة المرحلة العمرية أسئلة عن الحمل والولادة أو كيف نجىء للعالم، وقد يتبادل الأطفال فى العى

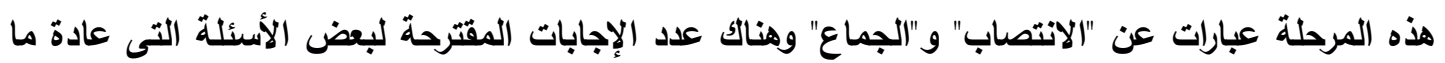
تجول فى خاطر الأطفال فى هذه السن:

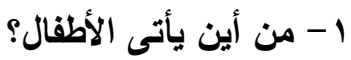
من مكان مخصوص داخل جسم المرأة يسمى الرحم.

\footnotetext{
1 - Home care.
} 
r - ب - بيف يصل الأطفال هناك؟

عندما بحب الرجل المرأة (ويجب هنا دمج القيم الخاصة بالمجتمع). والرجل لايه حيوان منوى والمرأة لايها بويضة. والحيوان المنوى للرجل يلقح بويضة المرأة وينمو الطقل.

r- كيف يتلاقى الحيوان المنوى والبويضة معاً:

الحيوان المنوى يُخلق فى خصيتى الرجل، والبويضة تأتى من مبيضى المرأة (وهنا يمكن إدراج بعض

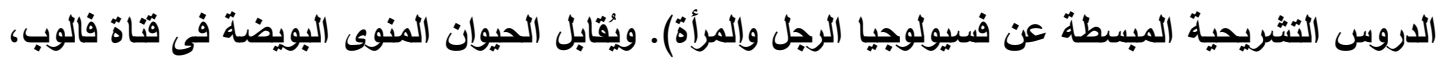

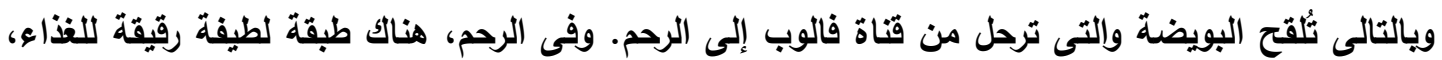
والبويضة الملقحة تبدأ فى النمو هناك.

ـ - كيف ياخل الحيوان المنوى فى جسم المرأة؟ عندما يتزوج الرجل المرأة (ويجب هنا دمج القيم الخاصة بالمجتمع)، الرجل يضع عضوه داخل مهيل

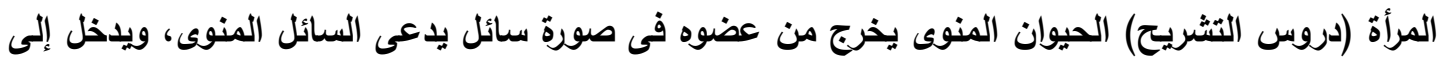

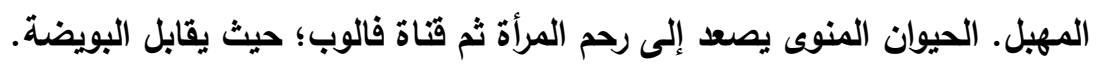

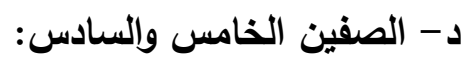

هذه السن هى السن الملائمة لإعطاء دروس أكثر تفصيلاً فى التشريح عن الجهاز التناسلى وعن كيفية تكوين السائل المنوى والتبويض والدورة الثهرية والحفاضات الصحية (للإناث) والأحلام المبللة أو الاحتلام الليلى والعادة السرية أو الاستمناء. ويجب أيضاً هنا تناول التغيرات الجنسية الثانوية التى تصاحب البلوغ ومرحلة المراهقة فيما بعد. هـ- ما بعد مرحلة البلوغ وحتى الرشد: يمكن تقديم كل محاور التربية الجنسية بمعناها الكامل مثل مهارات التفاعل الاجتماعى وتكوين الصدقات والاحتفاظ بها والأمن الثخصى.... إلخ.

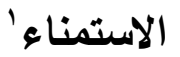

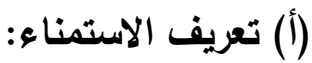
هو أحد أثكال الإثارة الذاتية 'للأعضاء التناسلية. وقاء يكون الاستمناء منفرداً أو مشتركاً بين أكثر من

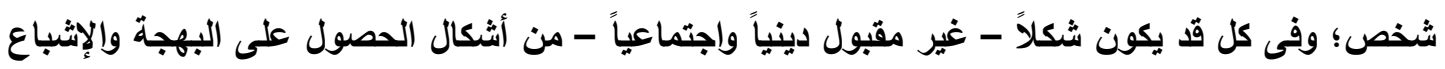

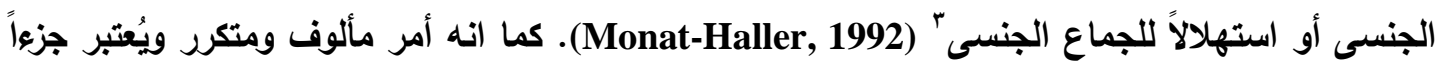
من استكثاف الأت؛ (Haka-lkse \& Mian, 1993). والاستنماء لاى المتخصصين فى التربية الجنسية فى الغرب نثاط طبيعى بل وصحى لكل من الإناث والذكور. لأنه يخفف التوتر الجنسى ومصدر لتعليم كثير

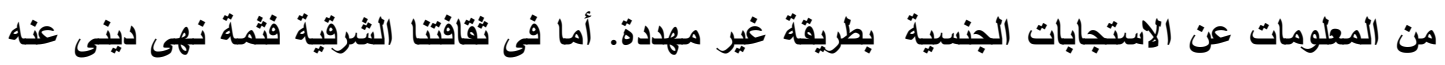

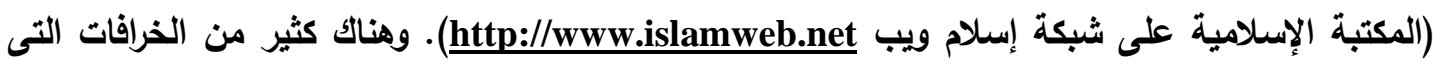
تحيط بالاستنماء ومنها أن من يمارسه سيصاب بالعمى أو سيكون لايه يدين مشعرتين. ولكن كثيراً من

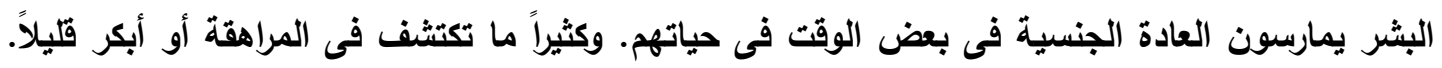

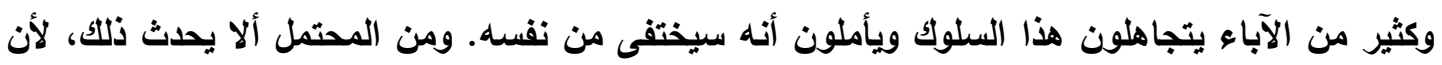

\footnotetext{
1 - Masturbation .

2 - Self-stimulating .

3 - Sexual intercourse .

${ }^{4}$ - Self-discovery .
} 
الاحتياجات الجنسية والرغبات تظهر على مدى الحياة. ومن المهم أيضاً أن نتذكر أن بعض الناس يكون

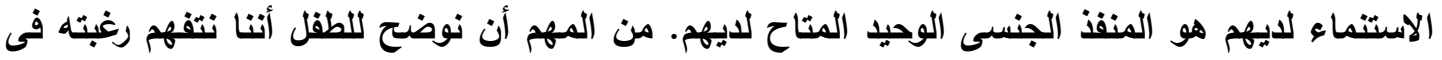

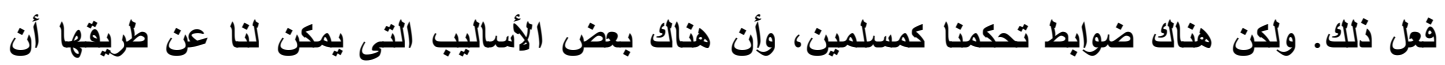

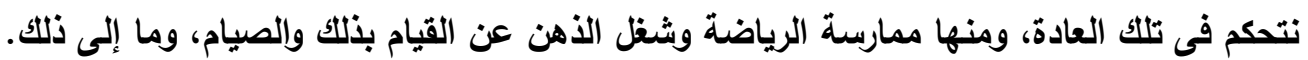
(ب) الاستمناء لاى ذوى الاحتياجات الخاصة:

أشارت إحدى الدراسات القديمة (Gebhard,1973) إلى أن نسبة حدوث الاستمناء لاعى عينة الأكور

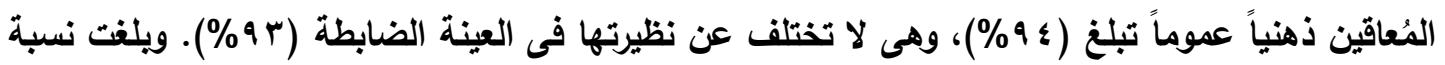

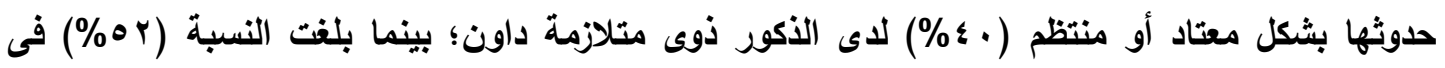

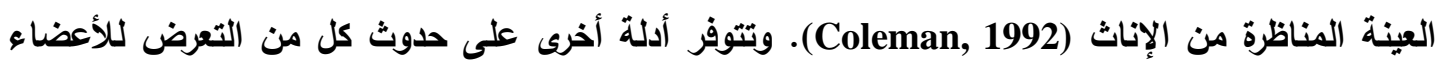

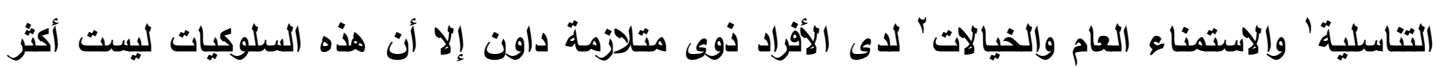

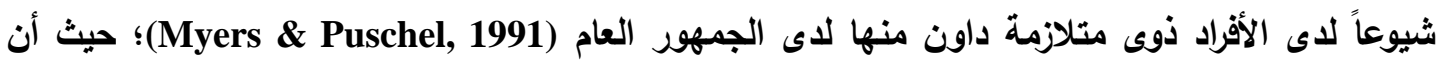

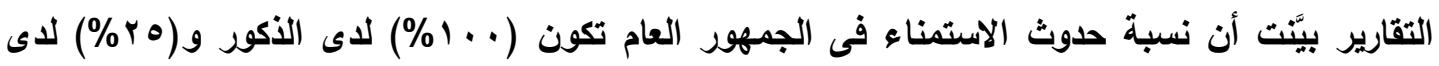

الإناث مع بلوغ عمر خمس عشرة سنة (Etem \& Leventhal, 1995).

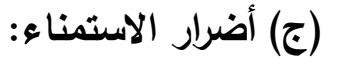

يمكن أن يسبب الاستمناء أذى أو ضراً للفرد، وهو ما يُلاحظ أكثر لاى الأفراد شديدى الإعاقة الذهنية؛

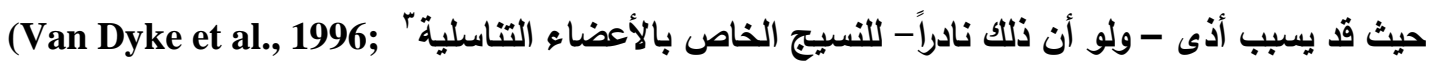

.(Van Dyke et al., 1995

$$
\text { الإساءة الجنسية: }
$$

يسود الآن توجه مؤداه أن الأطفال والمراهقين البالغين المعاقين ذهنياً مستهدفون بصفة خاصة للإساعة

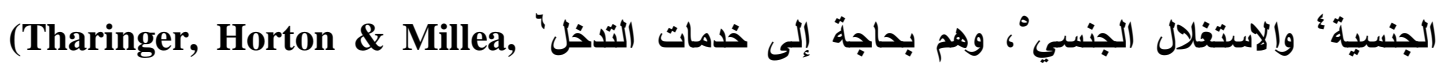
(1990. ويرجع هذا الاستهاف للاستغلال الجنسي - من وجهة نظر ثارينجر وهورتون وميلا (1990) -

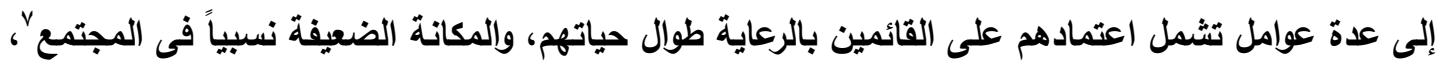

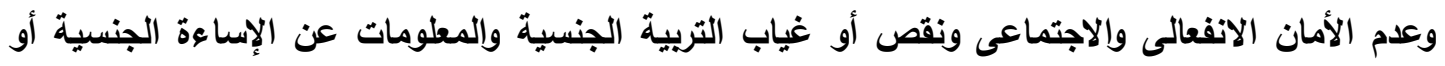
الاستغلال الجنسي. ويضاف إلى ذلك أن بعض المدربين والقائمين بالرعاية لايدركون جيداً المعنى الوظيفى الإنى

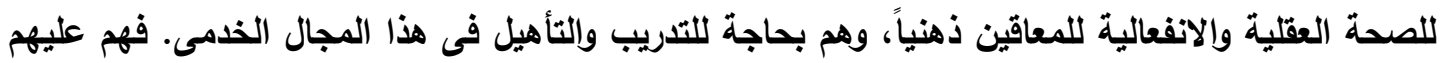

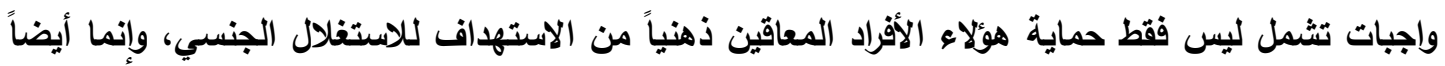
تزويدهم بالتخلات الملائمة إذا حلث استغلال جنسى، وأن يحترموا حقهم فى الحصول على المعرفة -

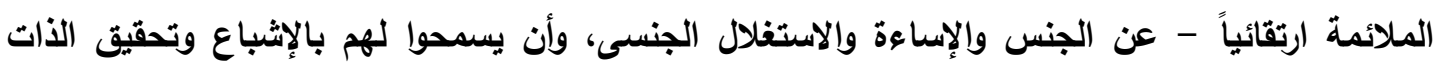

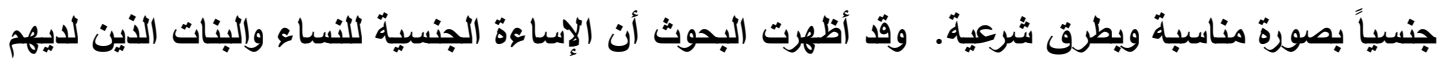

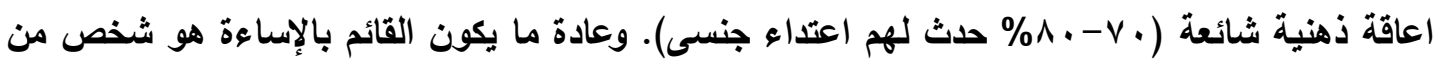

\footnotetext{
1 - Genital exposure.

2 - Fantasies .

3 - Genital tissue injury .

4 - Sexual abuse.

5 - Exploitation.

6 - Intervention services.

7 - Relatively powerless position in society.
} 
دائرة الأصدقاء أو الأسرة أو العاملين بالدعم وليسوا غرياء. واظهرت دراسة حديثة أن الغرباء يمثلون فقط

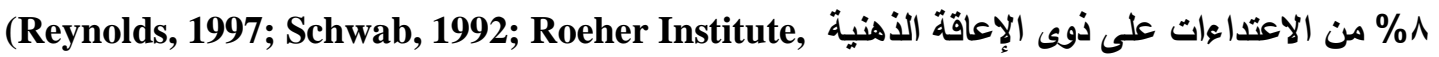
(1992. ويجب أن نفرق بين الإساءة والإعتداء، فالإساءة' تستخدم لوصف إنتهاك لحقوق الطقل متضمنة خرقاً للقانون المدنى، ومن أمثلة ذلك عرض الصور الجنسية، أو التحرش الجنسى. أما الاعتداء؟ فيتضمن خرقاً للقانون الجنائى، ويغطى كل الأفعال الجنسية التى تؤدى دون موافقة الضحية. سلوكيات الحماية:

تشمل سلوكيات الحماية عدداً من الخطط التى يتعلمها الأشخاص لكى يقللوا من امكانية تعرضهم

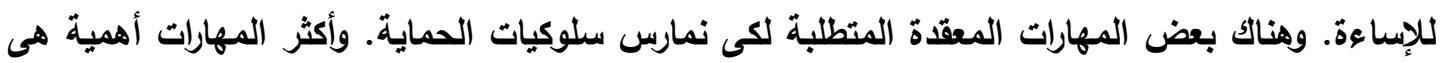

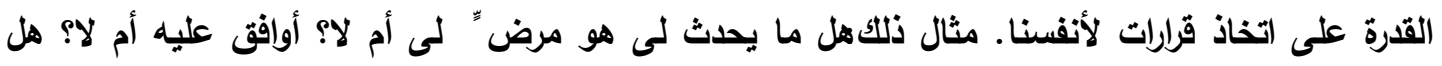

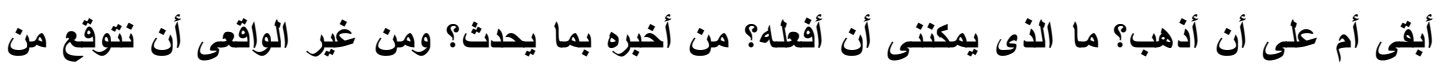

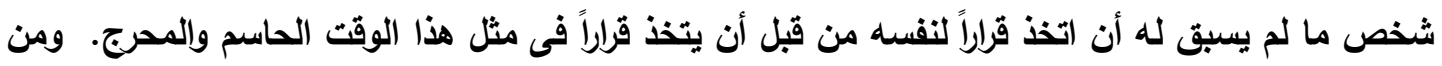

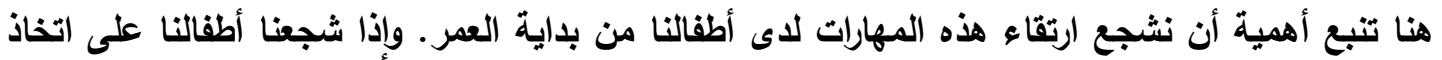

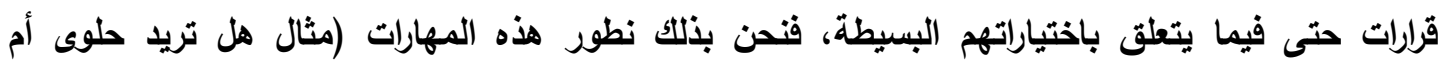

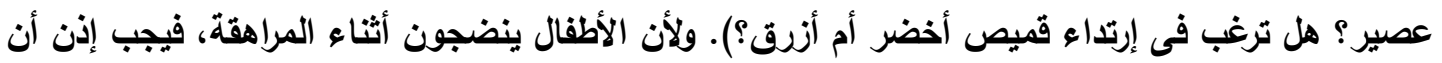

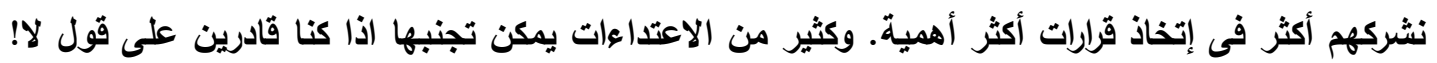

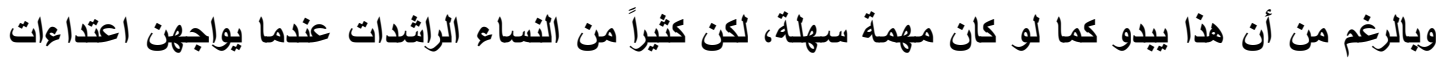

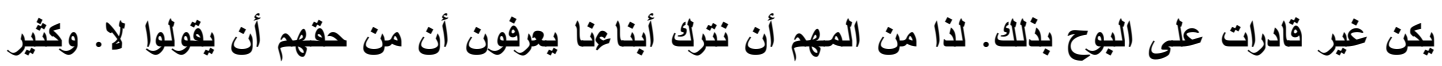

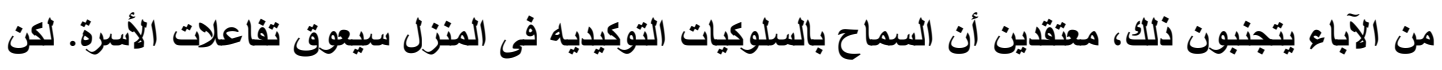

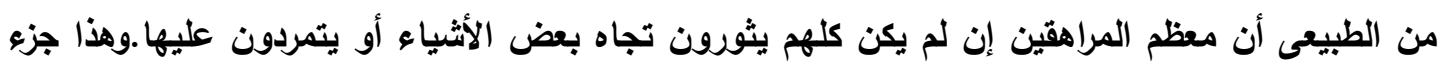

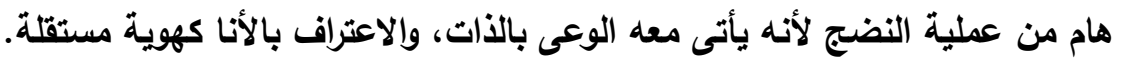

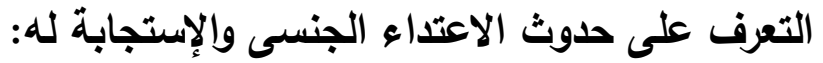

$$
\text { أولاً: المؤشرات الجسدية المحتملة: }
$$

هى عادة أكثر المؤثرات أو العلامات وضوحاً وصراحة لحدوث التحرش بالفعل أو إستمرار حدوثه. وهذه

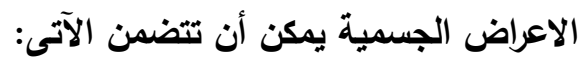
أ- صعوية فى المشى أو الجلوس.

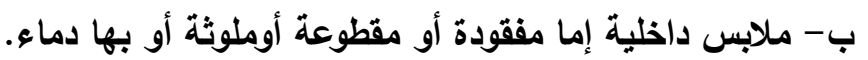

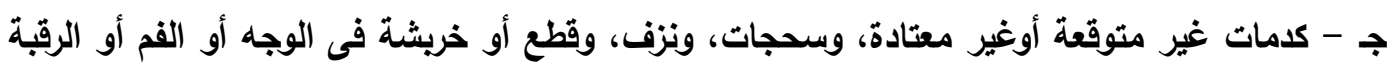

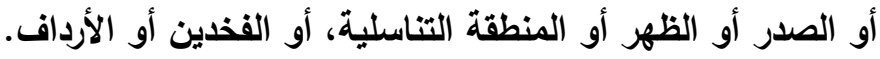

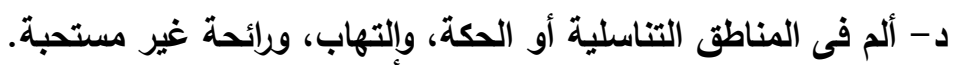

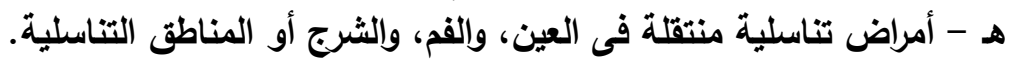
و - دم فى البول أو البراز. س- حمل. ح- قرحة فى المعدة غير متوقعة أو ألم فى البطن.

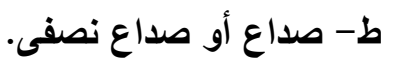
ى - أجسام غريبة فى الفتحات التناسلية أو الثرج. (Couwenhoven, 2007) 
ثانياً: المؤشرات السلوكية المحتملة: كثير من الأطفال الصغار أو فى المؤسسات الإيوائية أو المتأخرين عقلياً أو ذوى الإعاقات السمعية أو

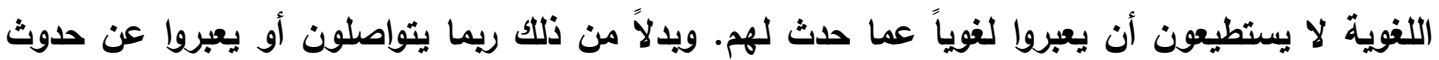
إساءة جنسية لهم من خلال التغيرات السلوكية. وهذه التغيرات ريما تتضمن:

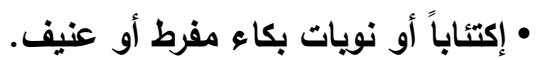

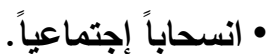

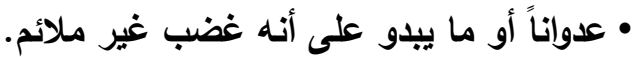

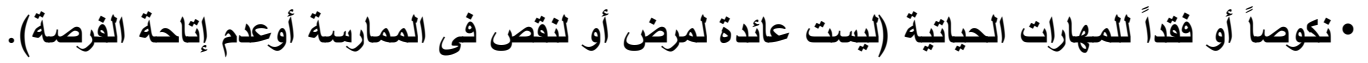
• الخوف، والتجنب، وممانعة فى التواجد مع أثخاص معينين أو فى أماكن معينة. • إضطرابات نوم، وكوابيس، ومشى أثناء النوم.

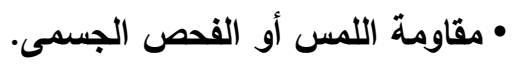
• باية سلوكيات تدمير أو إيذاء الذات (شد الشعر، قرص الجسم، خبط الرأس) وإيذاء الآخرين، وفقد الإحساس بالأمن الثخصى (سوء إستخدام العقاقير ، ونشاط جنسى عشوائى). • انخفاض تقدير الذات، ونقد الذات.

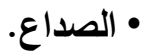
• باية اللمس الجنسى القهرى غير الملائم أو السلوكيات الجنسية أو التعليقات الجنسية والبحث عن مستويات جديدة من المعرفة الجنسية. • • نقص الاهتمام بالمظهر العام والتزين.

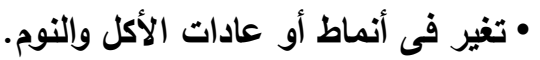
• ظهور أصوات جديدة (مثل الأزيز، الصراخ، الأنين).

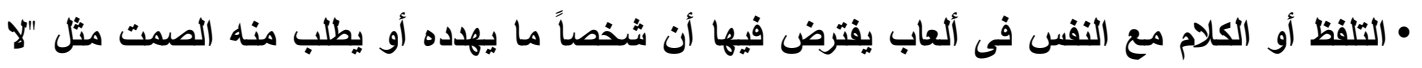

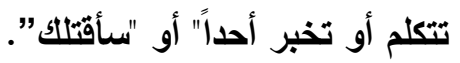
• النكوص لسلوكيات طفلية مثل (بلل الفراش، التلطيخ بالبراز).

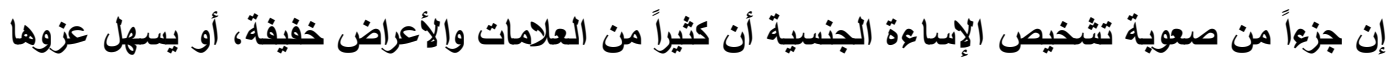
إلى أسباب أخرى صحية أو مشكلات طبية أوظروف حياتية حالية. وكمثال لذلك: ا - يمكن أن يرتبط فقد المهارات وإلنكوص بالإكتئاب. r - خبرة موت شخص محبوب يمكن أن يؤدى إلى تغيرات سلوكية أو أعراض شبه الإنه إكتئابية.

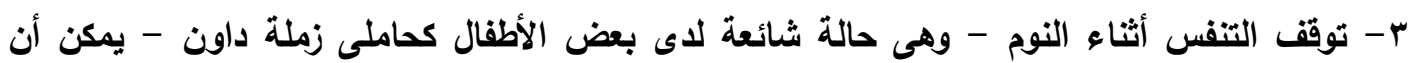
يؤدى إلى اضطرابات النوم، ونقص النوم يمكن أن ينتج عنه تغيرات سلوكية. ع - السلوك الجنسى غير الملائم ريما يرتبط بنقص معرفة الطقل واضطراب المهارة أكثر منه الإساءة .(Couwenhoven, 2007) ولكن الوالدان يعرفان طقلهما أفضل من أى شخص آخر، واذا ظهرت أى مجموعة من الأعراض السابقة فجأة لأسباب غير مفسرة، يجب أن لا يستبعدا الاستغلال كأحد الأسباب الممكنة. 
كيف نستجيب إذا حدثت إساعة للطقل؟

إذا تم اكتشاف حدوث اعتداء جنسى أو إساءة جنسية لأحد الأطفال، من المهم لنا كآباء أن نعرف كيف

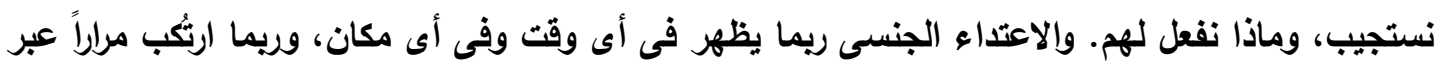

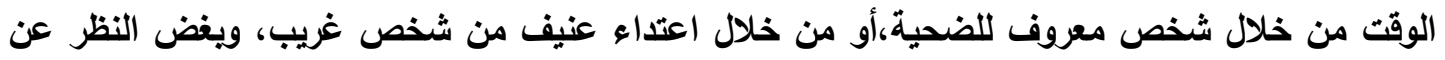

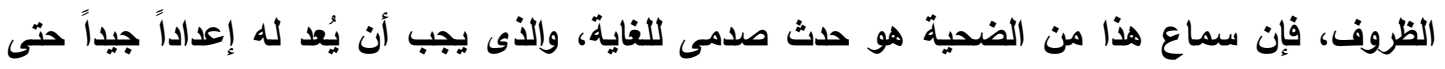
نعطى الرعاية الملائمة للثخص المعتدى عليه، وفى بعض الأحيان تُعطى هذه الرعاية والمساندة من الآباء هله

(خاصة الأم) وليس فقط المتخصصون. وفيما يلى بعض الخطط السلوكية التى يمكن الاسترشاد بها: * * الاحتفاظ بحالة الهاوء. * التأكيا على أمن الثخص الأطُ المُعتدى عليه فى ذلك الوقت.

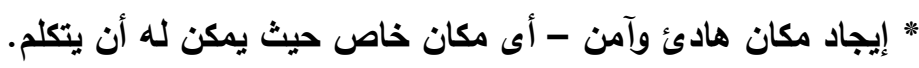

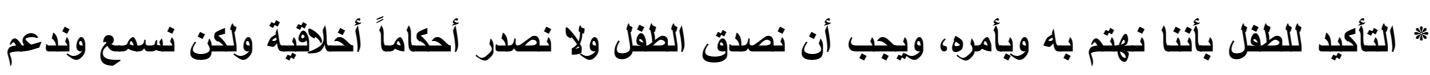

* اياً كان ما حلث يجب أن نتقل إليه أن هذا ليس خطأه وندعمه بعبارات المواساة.

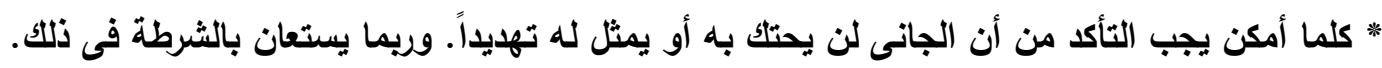

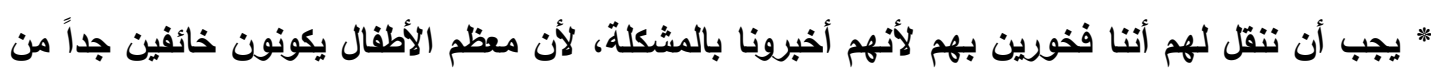
ذلك.

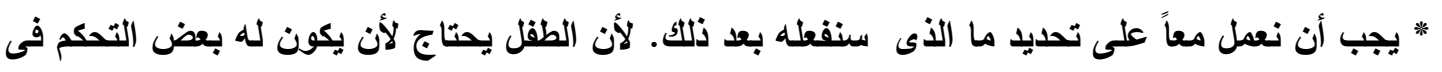

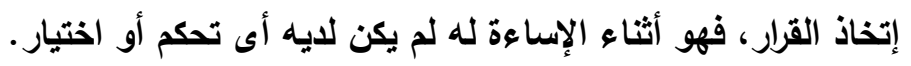

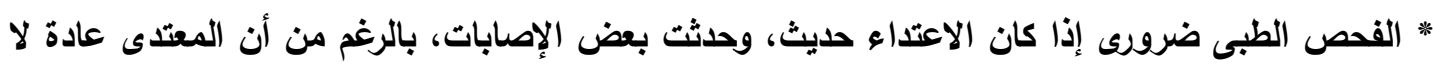
يقوم بالانزال، إلا أنه من الضرورى القيام بالفحص للوقاية من الأمراض الجنسية المتنقلة.

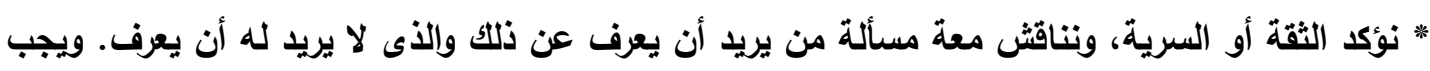
أن نتذكر أن الثخص الذى تعرض للإعتداء، عليه أن يواجه استجابات كل شخص سيعلم، مثلما هو مضطر أن يواجه أرجاعه الثخصية. * يجب اخبار المسئولين والسلطات. * يجب أن يكون الآباء قادرين على الاستجواب أيضاً منفصلين عن ابنهم. وإذا احتاج الأبوان أن يخبروا

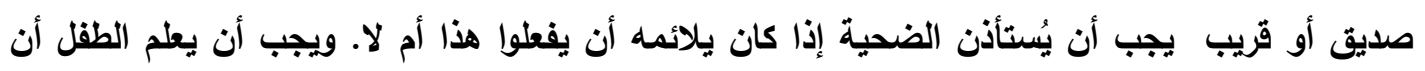

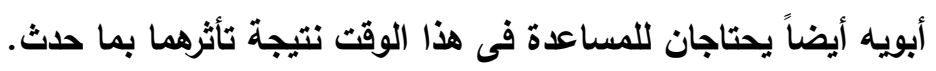

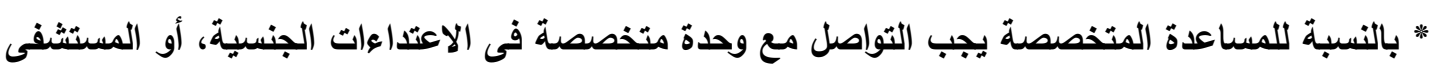

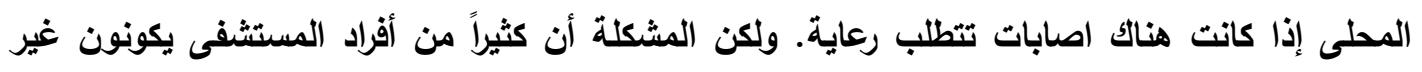

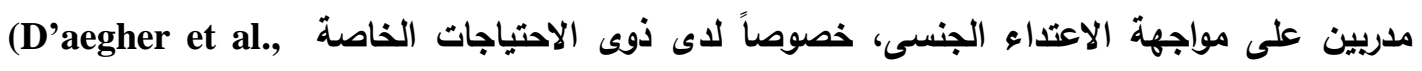




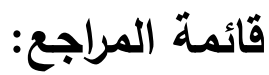

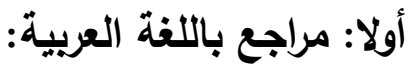

ا - إبراهيم قثققش (919 (19). سبكولوجية المراهقة. القاهرة: مكتبة الأنجلو المصرية. الطبعة الثالثة. r - الجمعية البحرينية لمتلازمة داون (ع . . ץ). كل شئ عن متلازمة داون. منشورة فى الموقع التالى: r- السيد سابق (799 ( 99 ). فقه السنة، (المجلد الأول). القاهرة: دار الفتح للإعلام العربى.

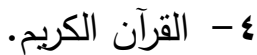

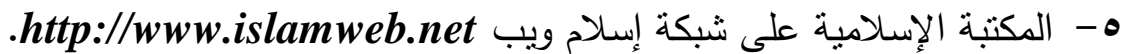

צ- حامد عبد السلام زهران (9VV ( ). علم نفس النمو: الطقولية وإلمراهقة. القاهرة: عالم الكتب.

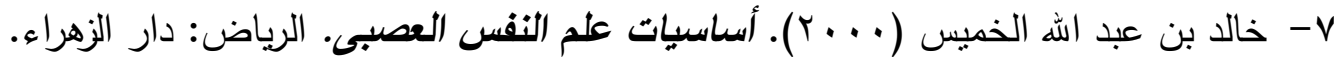

^- عبد الرحمن طالب الجزائرى (Y99 (1)). التربية الجنسية. القاهرة: الدار المصرية للنشر والتوزيع.

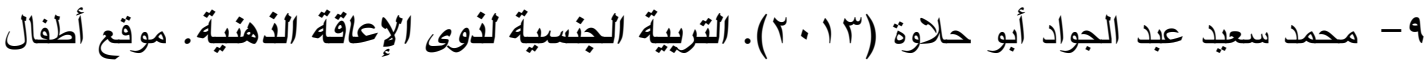
الخليج ذوى الاحتياجات الخاصة:

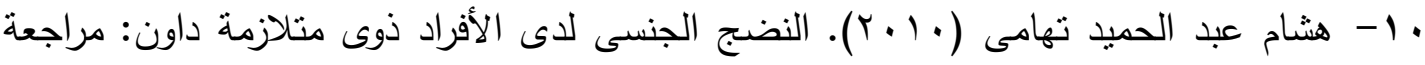

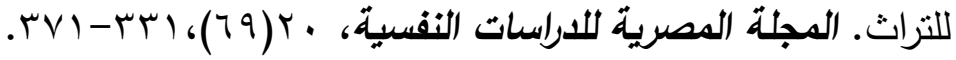

1 - ايوسف ميخائيل أسعد (بدون تاريخ). رعاية المراهقين. القاهرة: دار غريب للطباعة والنشر والتوزبع. ثانيا: مراجع باللغة الأنجليزية:

\section{References:}

12- Baker, Bruce \& Brightman, Alan (2004). Steps to Independence:

Teaching Everyday Skills to Children with Special Needs. Paul Brookes Publishing.

13- Berman, L. (2013). The Sex Ed Handbook. A comprehensive guide for parents. $\underline{w w w . o p r a h . c o m}$.

14- Cole, L. \& Hall, I. N. (1970). Psychology of adolescence. New York: Holt,Rinehart \& Winston Inc.

15- Coleman, M. (1992). Medical care in Down syndrome: A preventive medicine approach. New York: Dekker.

16- Couwenhoven, Terri (2007). Teaching Children with Down syndrome About their Bodies, Boundaries, and Sexuality: A Guide for Parents and Professionals. U.S., Woodbine House Inc.

17- Craft, A. \& Craft, M. (1985). Sexuality and relationships. In Craft, Bicknell \& Hollins (Eds.). Mental handicap. Pp177-196. Philadelphyia: Baillaire Tindall. Cited in the following site:

http://www.Sarasota.usf.edu/special education/mr classes/mrsexuality.htm. 
18- D’aegher, L., Robinson, P., Jones, S. \& Collier, M. (1999). Talk to me: A person development manual for women and girls with down syndrome, and their parents. Down syndrome Association of NSW Inc, Sydney, Australia.

19- De Jonge, F., Louwerse, A., Ooms, M., Evers, P., Endert, E., \& Van de poll, N. (1992). Changes in male copulatory behavior after sexual exciting stimuli: Effects of medial amygdala lesions. Physiology and behavior, 52, 327-332.

20- De Vries, G. (1990). Sex differences neurotransmitter system. Journal of Neuroendocrinology, 2, 1-13.

21- Drury, John; Hutchinson, Lynne \& Wright, Jon (2000). Holding On Letting Go: Sex, Sexuality and People with Learning Disabilities. London, Souvenir Press.

22- Edwards, J. (1988). Sexuality, marriage and parenting for person with Down Syndrome. In S. M. Pueschel, The young person with Down Syndrome, 187-204, Baltimore: Paul H. Brookes.

23- Engle, Beverly (1997). Beyond the Birds and the Bees: Fostering Your Child's Healthy Sexual Development in Today's World. Pocket Books.

24- Etem, I. \& Leventhal, J. M. (1995). Masturbation. In: S. Parker \& B. Zuckerman (Eds.), Behavioral and developmental pediatrics, pp 200-202, Boston: Little Brown \& Co.

25- Gebhard, P. H. (1973). Sexual behavior of the mentally retarded. In: F. F. De la Cruz \& G. D. Laveck (Eds.), Human sexuality and the mentally retarded. Proceedings of a conference on human sexuality and the mentally retarded. New York: Brunner/ Mazel.

26- Gillooly, Jessica B. (1998). Before She Gets Her Period: Talking With Your Daughter About Menstruation. Perspective Publishing.

27- Grant, L. (1995). Sex and the adolescent. In: S. Parker \& B. Zwellerman (Eds.), Behavioral and Developmental Pediatrics, 269-277, Bosten: Little Brown \& Co.

28- Hadley, Mac E. (1996). Endocrinology. Prentice Hall. Upper Saddie River, N J 07458.

29- Haffner, Debra (2000). From Diapers to Dating: A Parent's Guide to Raising Sexually Healthy Children. U.S., Newmarket Press. 
30- Haffner, Debra (2001). Beyond the Big Talk: Every Parent's Guide to Raising Sexually Healthy Teens. Newmarket Press.

31- Haka-Lkse, K. \& Mian, M. (1993). Sexuality in children. Pediatrics in review, 14(10), 401-407.

32- Hsiang, Y. H., Berkovitz, G. D., Bland, G. L., Migeon, C. J. \& Warren, A. C. (1987). Gonadal function in patients with Down Syndrome. American Journal of Medical Genetics, 27, 449-458.

33- Johnson, W. R. (1973) Sex education of the mentally retarded. In: F. F. De la Cruz \& G. D. Laveck (Eds.) Human sexuality and the mentally retarded. Proceedings of a conference on human sexuality and the mentally retarded. New York: Brunner/ Mazel.

34- Johnson, 1981: reported in Haight, S. L. \& Fachting, D. D. (1986). Materials for teaching sexuality, love and maturity to high school students with learning disabilities. Journal of Learning Disabilities, 19, 344-350.

35- Kelly, P. A. (1990). Growth hormone and Prolactin. In E.- E. Bauliey, \& P.A. Kelly (Eds), Hormones. From Molecules to disease. London: Chapman \& Hall, Inc.

36- Kinsey Institute for Research in Sex, Gender, and Reproduction. http://www.kinseyinstitute.org/publications/books.html

37- Labrie, F. (1990). Glycoprotein hormones: Gonadotropins and thyrotropin. In E.- E. Bauliey, \& P.A. Kelly (Eds), Hormones. From Molecules to disease. London: Chapman \& Hall, Inc.

38- Maksym, Diane (1990). Shared Feelings: A Parent Guide to Sexuality for Children, Adolescents, and Adults Who Have a Mental Handicap. Downsview, Ont., The G. Allan Roeher Institute.

39- Manikam, R. \& Hensarling, D. S. (1990). Sexual behavior. In J. L. Matson (Ed.), Handbook of behavior modification with mentally retarded. New York and London: Plenum press.

40- Mc Coy, E. E. (1991). Endocrine function in Down Syndrome. In I. T. Lott \& E. E. Mc Coy (Eds.), Down Syndrome advances in medical Care, 71-82, New York: Wiley-Liss.

41- Monat-Haller, R. K. (1992). Understanding and expressing sexuality. Baltimore MD: Paul H. Brookes Co. 
42- Moreira, Lilia Maria De Azevedo \& Gusmao, Fabio A. F. (2002). Genetic and social aspects of down syndrome subjects' sexuality. Revista Brasileira De Psiquiatria, 24(2), Jun, 94-99.

43- Morgenstern, M. (1973). The psychosexual development of the retarded. In: F. F. De la Cruz \& G. D. Laveck (Eds.) Human sexuality and the mentally retarded. Proceedings of a conference on human sexuality and the mentally retarded. New York: Brunner/ Mazel.

44- Myers, B. A. \& Pueschel, S. M. (1991). Psychiatric disorder in a population with Down Syndrome. Journal of Nervous and mental disease, 179, 609-613.

45- National Information Center for Children and Youth with Disabilities (1992). Sexuality education for children and youth with disabilities. Digest, ND 17, home page, http://www.nichcy.org.

46- Nelson, R. J. (2000). An introduction to behavioral endocrinology. Sunderland,Massachusetts: Sinauer Associates, Inc. Publishers.

47- Nigro, G. (1975). Sexuality in the handicapped: Some observations on human needs and attitude. Rehabilitation literature, 36, 202-205.

48- Ozalap, S.; Bombas, T.; Trindade, M. J.; \& Branco, P. (2001). Practical Aspects of sexual education. Faculty of medicine, department of obstetrics and gynecology. Turkey, Osmangazi university press.

49- Pueschel, S. M. (2001). Young person with Down Syndrome: Transition from adolescence to adulthood. Published in the following site: http://www.ndss.org/content.cfm?fuseaction=searchlink\&article=227.

50- Pueschel, S. M. \& Bier, J. A. B. (1992). Endocrinologic aspects. In S. M. Pueschel \& J. M. Pueschel (Eds), Biomedical concerns in persons with Down Syndrome, 259-272, Baltimore MD: Paul H. Brookes.

51- Roeher Institute (1992). No More Victims: A Manual to Guide Family and Friends in Preventing the Sexual Abuse of People with a Mental Handicap. www.roeher.ca/english/about/about/htm.

52- Reynolds, L. a. (1997). People with mental retardation \& sexual abuse. Published in the following site: http:thearc.org/faqs/sexabuse.html.

53- Schupf, Nicole; Pang, Deborah; Patel, Bindu N.; Silverman, Wayne; Schubert, Romaine; Lai, Florance; Kline, Jennie K.; Stern, Yaakov; Ferin, Michel; Tycko, Benjamin \& Mayeux, Richard (2003). Onset of dementia is 
associated with age at menopause in women with down's syndrome. Annals of Neurology, 54(4), Oct., 433-438.

54- Schwab, W. E. (1992). Sexuality and community living in Down Syndrome: Advances in medical care. New York: Wiley-Liss.

55- Schwab, W. (2001). Sexuality in Down Syndrome. Published in the following site:

56- http://www.ndss.org/content.cfm?fuseaction=InfoRes//lthArticle\&ariticle=43.

57- Schweir, Karin Melberg \& Hingsburger, David (2000). Sexuality: Your Sons and Daughters with Intellectual Disabilities. Paul H. Brookes Publishing.

58- Scola, P. S. \& Pueschel, S. M. (1992). Menstrual cycles and basal body temperature curves in women with Down Syndrome. Obstetrics and Gynecology, 79, 91-94.

59- Tharinger, Deborah; Horton, Connie Burrows \& Millea, Susan (1990). Sexual abuse and exploitation of children and adults with mental retardation and other handicaps. Child Abuse and Neglect, 14, Issue 3,301-312.

60- Van Dyke, D.C., McBrien, D.M. \& Mattheis, P.J. (1995). Psychosexual behavior, sexuality and management issues in individuals with Down Syndrome. Presentation, European Down Syndrome Symposium. Mallorca, Spain.

61- Van Dyke, D.C., McBrien, D.M. \& Mattheis, P.J. (1996). Psychosexual behaviour, Sexuality and management issues in individuals with Down's Syndrome. In: J.A. Rondal, J. Perera, L. Nadel \& A.Comblain (eds.), Down's syndrome. Psychological, Psychobiological and socio-educational perspectives. Singular Publishing Group, Inc. San Diego, California.

62- Walker-Hirsch, Leslie (2002). Building relationships/social and sexual development. In: William I. Cohen; Lynn Nadel; et al. (Eds.), Down syndrome: Visions for 21st century. 305-315. New York, NY, US: WileyLiss.

63- Walker-Hirsc, L. \& Champagne, M. P. (1992). Circles III: safer ways. In: A. C. Crocker, H. J. Cohen \& T. A. Kastner (Eds.), HIV infection and developmental disabilities, pp147-158, Baltimore M D: Paul H. Brookes Co.

64- Wroble, Mary (2003). Taking Care of Myself: A Hygiene, Puberty and Personal Curriculum for Young People with Autism. Future Horizons. 


\title{
Sex Education
}

Nermin AbdElwahab Ahmed

Department of psychology

Beni-Soueif university

\author{
Hesham Abd Elhamid Tohamy \\ Department of psychology \\ Beni-Soueif university
}

\begin{abstract}
:
This paper aimed at discussing a problematic issue; sex education. Topics covered are the importance of sex education, difference between sex and sex education, objectives of sex education, sources and components of sex education, questions frequently asked by parents, sex education support and protective procedures. In addition to that masturbation and sexual abuse are addressed.
\end{abstract}

